OPEN ACCESS

Edited by:

Kai Deng,

Sun Yat-sen University, China

Reviewed by: Yang Qiu,

Chinese Academy of Sciences, China Siew Pheng Lim,

Denka Life Innovation Research (DLIR), Singapore

*Correspondence:

Shu-Cheng Hua hsc@jlu.edu.cn

Juan Du

jdu@jlu.edu.cn

Specialty section:

This article was submitted to

Virology,

a section of the journal

Frontiers in Microbiology

Received: 10 October 2020 Accepted: 23 November 2020

Published: 14 December 2020

Citation:

Wang S-H, Wang K, Zhao K,

Hua S-C and Du J (2020) The

Structure, Function, and Mechanisms

of Action of Enterovirus

Non-structural Protein 2C.

Front. Microbiol. 11:615965.

doi: 10.3389/fmicb.2020.615965

\section{The Structure, Function, and Mechanisms of Action of Enterovirus Non-structural Protein 2C}

\author{
Shao-Hua Wang ${ }^{1}$, Kuan Wang ${ }^{2}$, Ke Zhao ${ }^{1}$, Shu-Cheng Hua ${ }^{3 *}$ and Juan $\mathrm{Du}^{1,4 *}$ \\ ${ }^{1}$ Institute of Virology and AIDS Research, The First Hospital of Jilin University, Changchun, China, ${ }^{2}$ Department of \\ Neurotrauma, The First Hospital of Jilin University, Changchun, China, ${ }^{3}$ Department of Internal Medicine, The First Hospital of \\ Jilin University, Changchun, China, ${ }^{4}$ Key Laboratory of Organ Regeneration and Transplantation of the Ministry of Education, \\ The First Hospital of Jilin University, Changchun, China
}

Enteroviruses are a group of RNA viruses belonging to the family Picornaviridae. They include human enterovirus groups $\mathrm{A}, \mathrm{B}, \mathrm{C}$, and $\mathrm{D}$ as well as non-human enteroviruses. Enterovirus infections can lead to hand, foot, and mouth disease and herpangina, whose clinical manifestations are often mild, although some strains can result in severe neurological complications such as encephalitis, myocarditis, meningitis, and poliomyelitis. To date, research on enterovirus non-structural proteins has mainly focused on the $2 \mathrm{~A}$ and $3 \mathrm{C}$ proteases and 3D polymerase. However, another non-structural protein, 2C, is the most highly conserved protein, and plays a vital role in the enterovirus life cycle. There are relatively few studies on this protein. Previous studies have demonstrated that enterovirus $2 \mathrm{C}$ is involved in virus uncoating, host cell membrane rearrangements, RNA replication, encapsidation, morphogenesis, ATPase, helicase, and chaperoning activities. Despite ongoing research, little is known about the pathogenesis of enterovirus $2 \mathrm{C}$ proteins in viral replication or in the host innate immune system. In this review, we discuss and summarize the current understanding of the structure, function, and mechanism of the enterovirus $2 \mathrm{C}$ proteins, focusing on the key mutations and motifs involved in viral infection, replication, and immune regulation. We also focus on recent progress in research into the role of $2 \mathrm{C}$ proteins in regulating the pattern recognition receptors and type I interferon signaling pathway to facilitate viral replication. Given these functions and mechanisms, the potential application of the $2 \mathrm{C}$ proteins as a target for anti-viral drug development is also discussed. Future studies will focus on the determination of more crystal structures of enterovirus $2 \mathrm{C}$ proteins, which might provide more potential targets for anti-viral drug development against enterovirus infections.

\section{Keywords: enterovirus, $2 \mathrm{C}$ protein, structure, function, host immune response, type I IFNs, anti-viral drug}

\section{INTRODUCTION}

The Enterovirus (EV) genus consists of a large number of RNA viruses belonging to the family Picornaviridae, including human enterovirus groups A, B, C, and D as well as non-human enteroviruses (Zoll et al., 2009). Of these pathogens, enterovirus A71 (EV-A71) and coxsackievirus A16 (CV-A16) are the most common causative pathogens of hand, foot, and mouth disease (HFMD), 
which affect millions of people each year, especially infants and children under of 5 years age, in the Asian and Pacific regions (Wang et al., 2018). Although usually self-limiting, HFMD can lead to severe complications such as aseptic meningitis, acute flaccid paralysis, and neurological respiratory syndrome or fatal respiratory disease (Chang et al., 1998; Zell et al., 2017). However, other non-EV-A71 and non-CV-A16 human EV-A group pathogens, such as CV-A6, CV-A10, and $\mathrm{CV}-\mathrm{A} 4$, are predominant co-circulated serotypes which have been causing HFMD in China since 2013 (He et al., 2013; Li et al., 2018a; Ji et al., 2019; Xie et al., 2020).

Enteroviruses are non-enveloped, spherical viruses with a diameter ranging from 28 to $30 \mathrm{~nm}$, and single positive-stranded RNA. The genome of these enteroviruses is approximately $7.5-8.0 \mathrm{~kb}$ in length and contains one open reading frame (ORF), flanked by a highly structured 5'-untranslated region (5' UTR) and a 3' UTR with a poly(A) tail. The 5' UTR is composed of an RNA cloverleaf structure followed by an internal ribosomal entry site (IRES). The IRES is a highly structured RNA that directly recruits ribosomes for viral protein translation in a cap-independent manner (Fitzgerald and Semler, 2009). As shown in Figure 1, the genome is initially translated into a single large polyprotein of approximately 2,200 amino acid residues. This polyprotein is proteolyzed into $\mathrm{P} 1, \mathrm{P} 2$, and $\mathrm{P} 3$ precursor proteins, and is further cleaved co- and post-translationally by viral $2 \mathrm{~A}$, 3C, and 3CD proteases (Cameron et al., 2010; Lyoo et al., 2017). The $\mathrm{P} 1$ precursor protein is cleaved into the capsid proteins VP3, VP1, and VP0. VP0 is then further divided into VP4 and $\mathrm{VP} 2$. The P2 precursor protein is processed to form the viral protease $2 \mathrm{~A}$ and the $2 \mathrm{BC}$ polyprotein, and the $2 \mathrm{BC}$ polyprotein is further cleaved into two non-structural proteins, $2 \mathrm{~B}$ and $2 \mathrm{C}$. The $\mathrm{P} 3$ precursor protein is initially proteolyzed into $3 \mathrm{AB}$ and $3 \mathrm{CD}$, and then further proteolyzed to form proteins $3 \mathrm{~A}, 3 \mathrm{~B}$, 3C, and 3D (McMinn, 2002).

Most published studies have focused on enterovirus structural proteins or the non-structural $2 \mathrm{~A}$ and $3 \mathrm{C}$ proteases, and $3 \mathrm{D}$ polymerase, whereas the importance of the non-structural protein 2C has been relatively neglected. In this article, we summarize the structure, function, and mechanism of regulation of the host innate immune system and anti-viral drugs of the enterovirus $2 \mathrm{C}$ protein.

\section{COMMON FUNCTION OF ENTEROVIRUS 2C PROTEINS}

Enterovirus 2C protein is the most conserved and complex non-structural protein, but its functions are not well understood (Norder et al., 2011). Numerous biological functions of the $2 \mathrm{C}$ protein have been reported as part of the virus life cycle (Table 1), including virus uncoating (Li and Baltimore, 1990), host cell membrane rearrangements (Cho et al., 1994; Aldabe and Carrasco, 1995; Teterina et al., 1997; Suhy et al., 2000), RNA binding (Rodriguez and Carrasco, 1995; Banerjee et al., 1997, 2001; Banerjee and Dasgupta, 2001), RNA replication (Li and Baltimore, 1988; Rieder et al., 2000; Paul et al., 2003; Teterina et al., 2006; Tang et al., 2007), encapsidation and morphogenesis (Vance et al., 1997; Verlinden et al., 2000; Liu et al., 2010; Wang et al., 2012a, 2014), and ATPase activity (Rodriguez and Carrasco, 1993; Mirzayan and Wimmer, 1994).

The $2 \mathrm{C}$ protein was predicted to be an SF3 helicase, based on its AAA + ATPase activity and conserved SF3 motifs (Gorbalenya and Koonin, 1989; Rodriguez and Carrasco, 1993; Pfister and Wimmer, 1999). In 2015, it was first demonstrated that the $2 \mathrm{C}$ protein of EV-A71 and CV-A16 possesses ATP-dependent RNA helicase and ATP-independent chaperoning activities, which are critical for viral RNA replication (Xia et al., 2015). These results indicate that the RNA helicase and RNA chaperoning activities, two different RNA remodeling activities, can be integrated in the $2 \mathrm{C}$ protein, suggesting a vital role for the $2 \mathrm{C}$ protein in the remodeling of proteins by viral RNA (Xia et al., 2015).

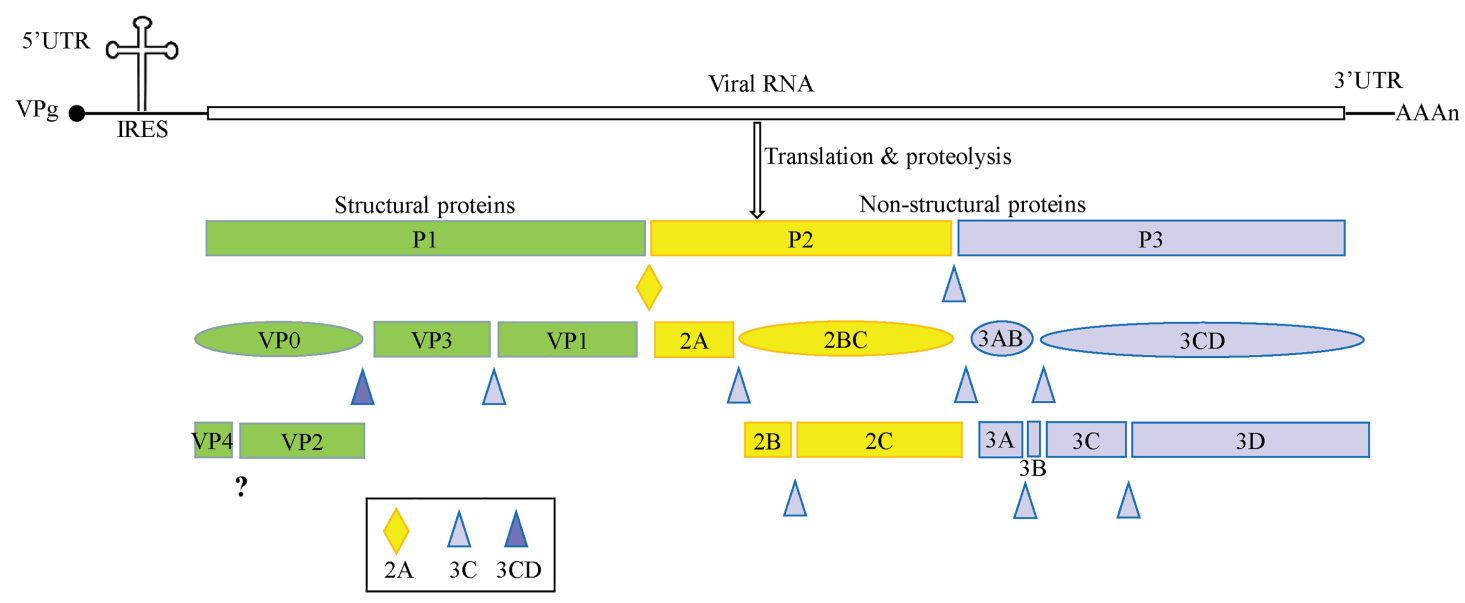

FIGURE 1 | A schematic representation of enterovirus A71 (EV-A71) genome and proteolytic processing of the polyprotein. The polyprotein was cleaved into four viral proteins, VP1-VP4, and seven non-structural proteins including 2A-2C and 3A-3D. 
TABLE 1 | The function of enterovirus non-structural $2 \mathrm{C}$ proteins.

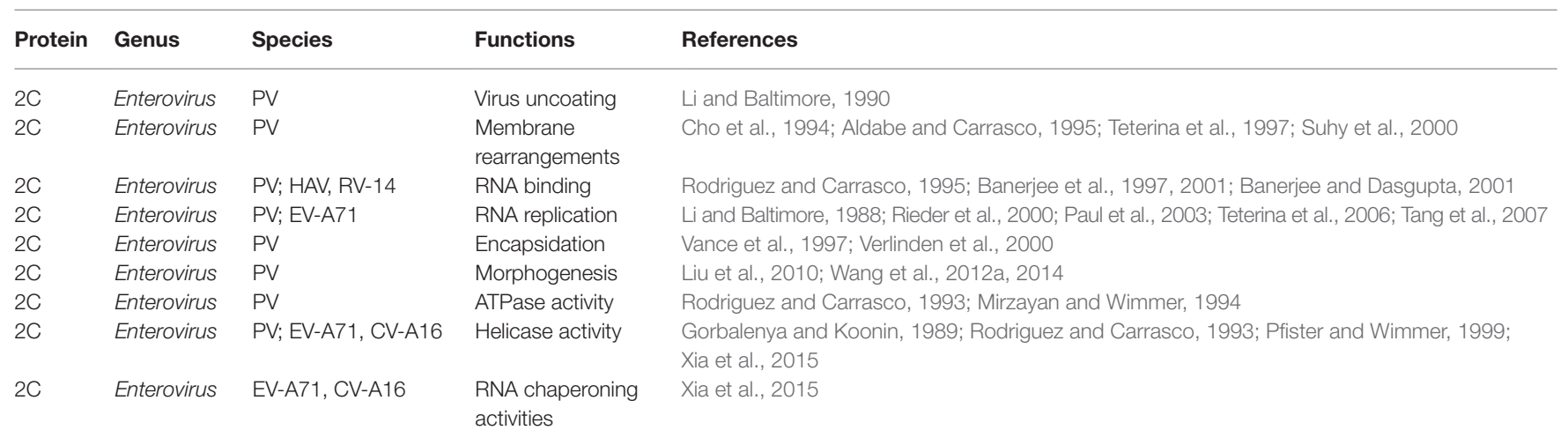

\section{THE RELATIONSHIP BETWEEN STRUCTURE AND FUNCTION OF 2C PROTEINS IN THE ENTEROVIRUS LIFE CYCLE}

The $2 \mathrm{C}$ protein typically has 330 amino acid residues. It contains an $\mathrm{N}$-terminal membrane-binding domain, a central ATPase domain, a cysteine-rich domain, and a C-terminal helical domain (Figure 2A; Banerjee et al., 2004). The ATPase domain of $2 \mathrm{C}$ exhibits the structural characteristics of the SF3 helicases of the AAA+ ATPase superfamily, which consists of Walker A and Walker B motifs, and motif C (Figure 2B; Singleton et al., 2007). Recently, the crystal structure of a soluble part (116-329 aa) of EV-A71 2C helicase was reported by Guan et al. (2017), the first high-resolution 2C structure in the Picornaviridae family. EV-A71 $2 \mathrm{C}$ has an unusual zinc finger with three cysteine ligands. However, unlike other ATPases, the C-terminus of EV-A71 2C forms an amphipathic helix that mediates self-oligomerization through a specific interaction between $2 \mathrm{C}-2 \mathrm{C}$, and self-oligomerization is fundamental to 2C ATPase activity and EV-A71 virus replication.

Poliovirus (PV) 2C protein is the most intensively studied 2C protein in the Picornaviridae family. Recently, Guan et al. (2018) reported a high-resolution structure of part of the PV 2C protein (116-329 aa). Their results indicated that the self-oligomerization mediated by the C-terminal helix of the PV $2 \mathrm{C}$ protein also occurred via a specific interaction between $2 \mathrm{C}-2 \mathrm{C}$, like that of EV-A71 2C. This interaction is vital to the protein's ATPase activity, and is a common feature in enterovirus $2 \mathrm{C}$ proteins. PV $2 \mathrm{C}$ and EV-A71 $2 \mathrm{C}$ possess almost identical geometry, and catalytic residues of the ATPase active site, which forms between these $2 \mathrm{C}$ subunits, and should have similar functions (Mirzayan and Wimmer, 1994; Pfister and Wimmer, 1999). However, the part of the protein which is most structurally different between PV $2 \mathrm{C}$ and EV-A71 $2 \mathrm{C}$ is the zinc finger. $\mathrm{PV} 2 \mathrm{C}$ has four potential zinc coordination sites (PCS1-4) in the cysteine-rich motif, suggesting a canonical CCCC type zinc finger, while EV-A71 2C and many other enterovirus $2 \mathrm{C}$ proteins have only a CCC type zinc finger, which lacks the PCS2 cysteine residue (Figure 2B).
It has been reported that the PCS2 of PV $2 \mathrm{C}$ is associated with temperature-sensitive phenotypes and encapsidation defects (Klein et al., 2000; Wang et al., 2014), but the zinc finger of EV-A71 2C, to which the PCS2 has been added by mutation, failed to improve its infectivity. Further studies indicated that PCS2 and PCS4 might interact with other proteins during encapsidation, while PCS1 and PCS3 are essential for maintaining the folding of the zinc finger and the entire hexamer (Guan et al., 2018). Therefore, the sequence and structure distinction of the $2 \mathrm{C}$ protein may be the basis for the specificity of the enterovirus $2 \mathrm{C}$ protein and may determine the processes in which it may be involved.

Numerous residues, drug-resistant sites, and functional motifs have been identified in the enterovirus non-structural $2 \mathrm{C}$ proteins, which are critical to differences in the corresponding 2C function (Figure 2A). The ATPase and helicase activities of the $2 \mathrm{C}$ protein are mainly affected by mutations in the Walker A motif (positions 129-136; Wang et al., 2014), Walker B motif (positions 172-177; Wang et al., 2014), Motif C (positions 217-223; Xia et al., 2015), and the R finger (R240 and R241; Guan et al., 2017). The residues buried in the hydrophobic core of the $2 \mathrm{C}$ protein were found to be essential for overall folding (Guan et al., 2018). It has been reported that mutations of the $2 \mathrm{C}$ protein at positions Q65, L125, and V218 are important to encapsidation and morphogenesis (Vance et al., 1997; Wang et al., 2014; Asare et al., 2016), while mutations at V218, M246, and I248 accounted for temperature sensitivity (Li and Baltimore, 1988; Dove and Racaniello, 1997). The mutations at L327 and F328, which are both located in the pocket-binding domain (PBD), can abolish the ATPase activity and homo-oligomerization of both $\mathrm{PV} 2 \mathrm{C}^{\mathrm{ATPase}}$ and EV-A71 2C helicases, and could suppress EV-A71 infection, indicating their essential role in the activity of $2 \mathrm{C}$ (Guan et al., 2017, 2018). Residues between 21-45 and 312-319 in the PV 2C protein are critical for RNA binding (Tolskaya et al., 1994), while residues 21-54 are important for membrane binding (Echeverri and Dasgupta, 1995), and positions 269-286 are essential for zinc binding (Klein et al., 2000). In addition, $2 \mathrm{C}^{\text {ATPase }}$ contains two amphipathic helixes at the $\mathrm{N}$ - and C-terminals, which could help anchor the protein to membranes and bind to zinc (Figure 2; Paul et al., 1994; Teterina et al., 1997; Wang et al., 2014). 
A

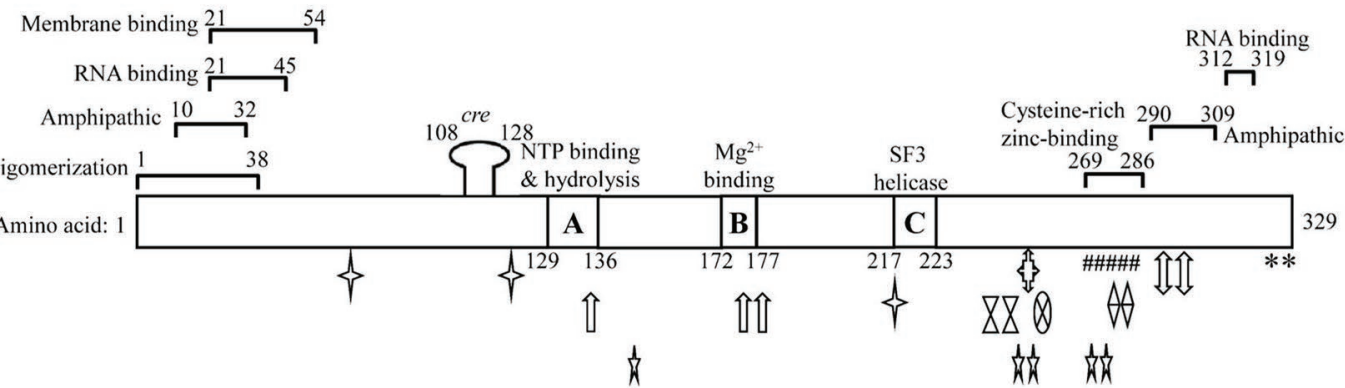

\& Morphogenesis Q65R, L125V, V218I (PV)

đf Uncoating M293V, K295R (PV)

$\$$ Capsid interacting N252S (PV)

$\theta$ Encapsidation K279A, R280A (PV)

Encapsidation/Uncoating K259A(PV)

$\triangle \mathrm{R}$ finger R240A, R241A (EV-A71, PV)

\# Zinc-binding site C269A (PV), C270A (EV-A71), C272A (PV), C281A (EV-A71, PV), C286A (EV-A71, PV)

\ATPase activity K135A (EV-A71, PV), D176N (EV-A71), D177A (PV)

* ATPase activity + Homo-oligomerization L327A, F328A (EV-A71, PV)

负 Temperature sensitivity E150A, M246A, I248A, C272A, H273A(PV)

B

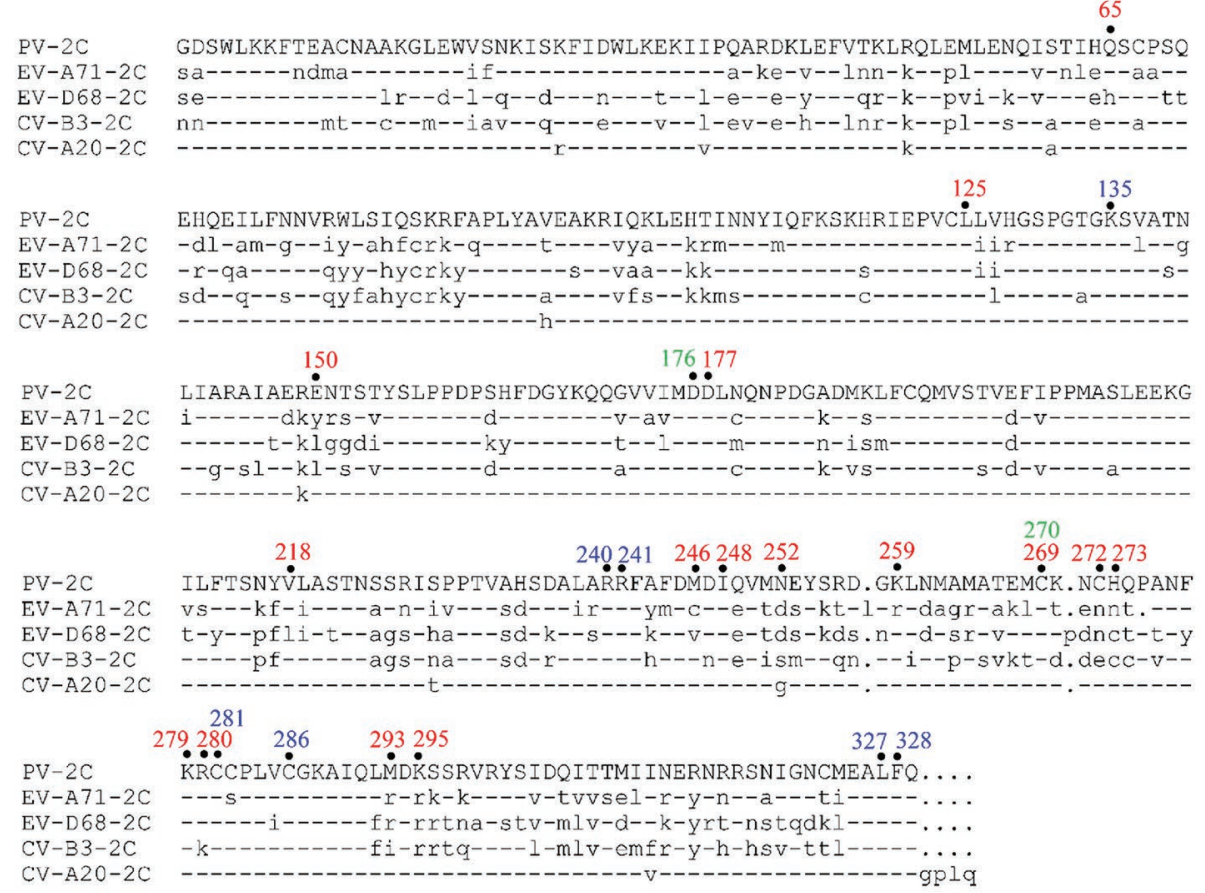

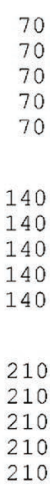

140

140

140

140

140

210

210

210

210

278

278

279

278

278

329

329

330

329

FIGURE 2 | Functional motifs and sequence alignment of enterovirus 2C protein. (A) Functional motifs in 2CATPase protein are shown in detail, including membrane binding-, RNA binding-, zinc binding-, oligomerization-, and amphipathic-motifs. The locations of the known mutations corresponding to morphogenesis, encapsidation, uncoating, capsid interacting, ATPase activity, homo-oligomerization, and temperature sensitivity are shown in different symbols. The precise positions of $\mathrm{R}$ finger and zinc-binding sites are indicated according to the crystal structural of EV-A71 2C protein. Amino acid positions in each motif are numbered and illustrated, and the exact species of each mutation is shown behind the amino acid position. (B) Sequence alignment of enterovirus $2 \mathrm{C}$ protein. The amino acid positions mentioned in (A) are highlighted on top of the sequences in different colors, with PV 2C in red, EV-A71 2C in green, and positions shared by both in blue. Dashes stand for amino acid residues identical to those of PV 2C protein.

Liu et al. (2010) found that the interaction site was between residue N252 of PV 2C and E180 of the capsid VP3 protein of $\mathrm{CV}-\mathrm{A} 20$, using a PV/CV-A20 chimera, indicating the essential role of N252 in encapsidation. The K259A mutant of PV 2C was found to play a vital role in encapsidation and the subsequent uncoating step during the next cycle of 
infection (Asare et al., 2016). Wang et al. (2012a) identified the K279 and R280 residues, which are located at the C-terminus of the PV 2C protein, as being involved in RNA replication and encapsidation. C270, C281, and C286 of the zinc finger were shown to be essential for correct folding of the EV-A71 2C protein (Guan et al., 2017). Previous studies have shown that both $2 \mathrm{C}$ and its precursor $2 \mathrm{BC}$ possess ATPase activity and can assist in the formation of an RNA replication complex with which to attach to membranes (Pfister et al., 2000). EV-A71 virus production was completely suppressed by key mutations in $\mathrm{K} 135 \mathrm{~A}$ and $\mathrm{D} 176 \mathrm{~N}$, which are located in the Walker A and $\mathrm{B}$ motifs, indicating an important role for the ATPase activity of $2 \mathrm{C}$ in virus replication. The ATPase activity of $2 \mathrm{C}$ could also be inhibited by mutations at R240 and R241, regardless of whether the amino acid was mutated to A or K, suggesting that the "R finger" may play an essential role in ATP hydrolysis (Guan et al., 2017).

RNA remodelers consist of two different types: RNA helicases and RNA chaperons. It has been reported that these highly structured RNA elements of viruses, especially RNA viruses, utilize RNA helicases or chaperons to ensure proper folding and re-folding (Xia et al., 2015). RNA helicases can unwind RNA duplexes using energy from ATP hydrolysis. However, RNA chaperones are a group of proteins that possess the ability to destabilize RNA duplexes, and could transform them to more stable RNA structures without RNA binding, or using energy from ATP hydrolysis (Musier-Forsyth, 2010; Yang et al., 2015). As with PV $2 C^{A T P a s e}$, the ATPase and helicase activity of EV-A71 2C could be inhibited by the GK134AA mutation, which abolishes the RNA replication and virus production of EV-A71, suggesting that the RNA remodeling activities introduced by $2 \mathrm{C}^{\text {ATPase }}$ are essential for enteroviral RNA replication and the life cycle. These RNA remodeling activities are also conserved in CV-A16 2C ${ }^{\text {ATPase }}$ (Xia et al., 2015). Further studies revealed that the C-terminal is critical for helicase activity, and the domains that account for RNA binding are required for the RNA chaperoning function of $2 \mathrm{C}^{\text {ATPase }}$ (Xia et al., 2015).

Internal ribosomal entry site, which is a highly structured element in the RNA genome, has been found within all picornaviruses and plays essential roles in the viral replication and translation process (Shih et al., 2011; Cheng et al., 2013). First, the IRES might need RNA chaperoning activity of $2 \mathrm{C}^{\text {ATPase }}$ to facilitate RNA strand annealing for proper folding and re-folding during viral replication. In addition, during RNA replication of the viral life cycle, the unwinding of the intermediate dsRNA is essential for efficient recycling of viral RNA template and subsequent progeny viral RNA production. In terms of the RNA replication of enterovirus, it is likely that the unwinding of dsRNA is performed by the RNA helicase activity of the $2 \mathrm{C}$ protein, as it was reported that the ATPase activity of EV-A71 2C can facilitate 3D-mediated enteroviral RNA synthesis in vitro by promoting the recycling of viral RNA template (Xia et al., 2015). Meanwhile, the defective ATPase and helicase activities of EV-A71 2C could almost abolish RNA replication and virus viability in an infectious clone experiment.

It has been reported that the AAA+ ATPase superfamily usually assembles into hexameric ring structure to perform proper functions (Gai et al., 2004; Enemark and Joshua-Tor, 2006). As EV-A71 2C and PV 2C both belong to this superfamily, they are known to form a hexamer ring, which will facilitate further understanding of $2 \mathrm{C}$ functions and provide important sites for the development of $2 \mathrm{C}$ inhibitors (Guan et al., 2017, 2018).

Enteroviruses $2 \mathrm{C}$ proteins participate in diverse processes and play multiple functions in the viral life cycle, based on the conserved $2 \mathrm{C}$ structures. The $\mathrm{N}$-terminal of the $2 \mathrm{C}$ protein possesses several essential motifs, which are associated with RNA binding, membrane binding, amphipathic, and oligomerization activities. Future studies will focus on the expression of more soluble full-length $2 \mathrm{C}$ proteins and the determination of the crystal structure of enterovirus $2 \mathrm{C}$ proteins. Crystallographic data would help us to better understand the relationship between the function and structure of $2 \mathrm{C}$ proteins, and to elucidate the detailed mechanism of the role of $2 \mathrm{C}$ proteins in virus replication and packaging.

\section{ENTEROVIRUS 2C PROTEIN BINDING TO VARIOUS HOST FACTORS}

Host factors play essential roles in the enterovirus life cycle, from viral entry to lytic release processes (Wu et al., 2016). To date, several host factors associated with the non-structural 2C protein have been reported to regulate viral replication (Figure 3). In 2007, Tang et al. (2007), using a two-hybrid experiment, reported the identification of reticulon 3 (RTN3), a member of the reticulon family of proteins, as a binding partner of the EV-A71 $2 \mathrm{C}$ protein in regulating the formation of the viral replication complex, a common cellular factor among CV-A16 and PV $2 \mathrm{C}$ proteins. These results indicate that the N-terminal of the $2 \mathrm{C}$ protein could interact with RTN3. The I25 amino acid residue of EV-A71 2C was found to play a key role in the interaction between $2 \mathrm{C}$ and the reticulon homology domain (RHD) of RTN3. A similar function can also be observed in the PV 2C protein, in which the I25K mutation of $2 \mathrm{C}$ can regulate viral protein processing and RNA replication (Paul et al., 1994). Specific interactions between the C-terminal RHDs of all four RTN family proteins and EV-A71 2C were also demonstrated (Tang et al., 2007).

In 2016, Wu et al. (2016) used a genome-wide RNAi screen in human RD cells and identified 256 host factors involved in EV-A71 replication. Among these factors, the cell cycle regulators aurora kinase B (AURKB) and cyclin-dependent kinase 6 (CDK6) were shown to be resistance factors restricting EV-A71 infection, with the nuclear egress of CDK6 regulated by EV-A71. However, the endoplasmic reticulum (ER)-associated degradation (ERAD) components, N-glycanase 1 (NGLY1), and valosin-containing protein (VCP) were identified as hostsupportive factors that facilitate EV-A71 infection and replication. Further studies revealed the colocalization of NGLY1 and EV-A71 replication complexes at the ER to support EV-A71 replication (Wu et al., 2016). Previous studies have shown that p97 is a host factor for PV (Arita et al., 2012) and is essential for hepatitis C virus (HCV) replication (Yi et al., 2016). 


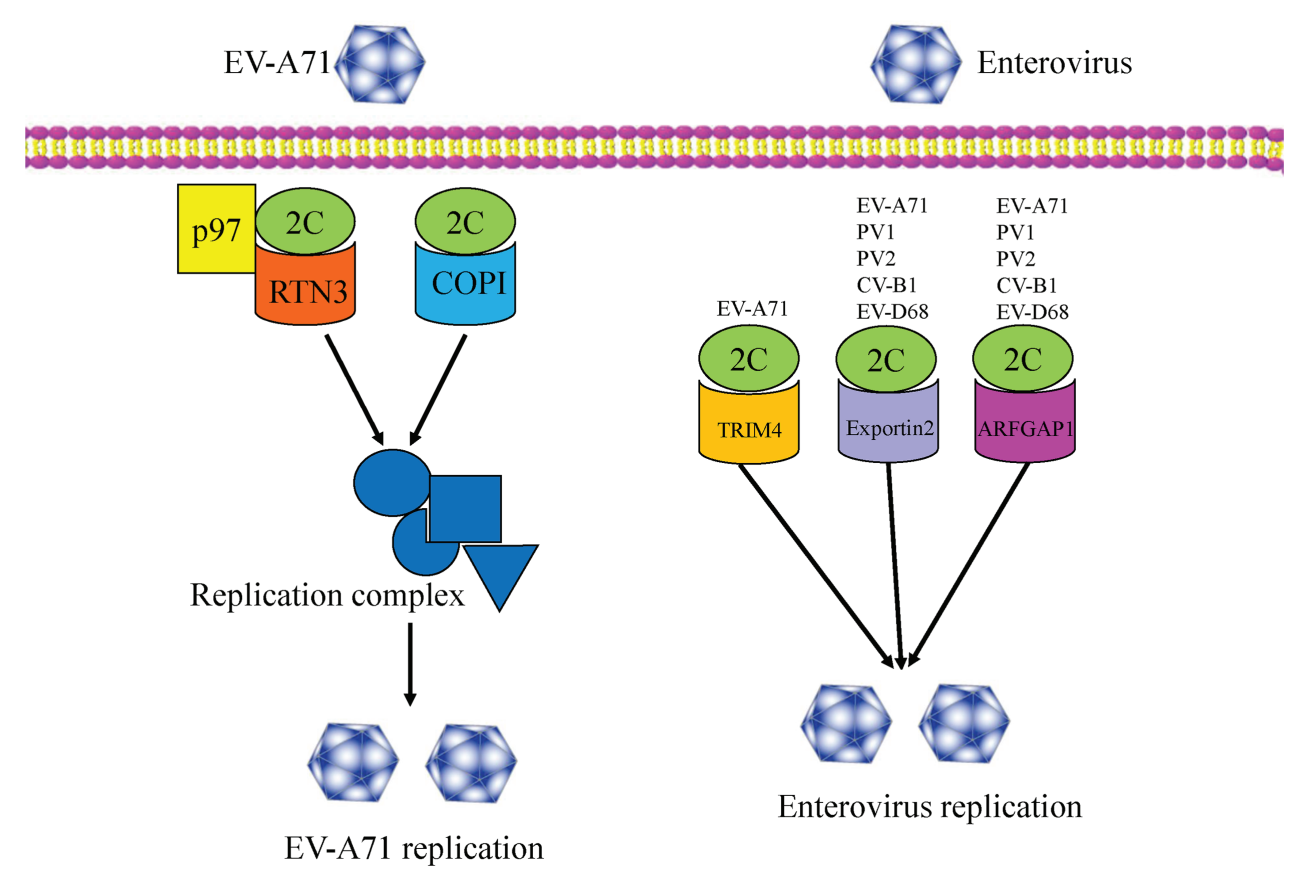

FIGURE 3 | An overview of the functions of enterovirus 2C proteins, which interact with several host factors and regulate viral replication and infection.

Wang et al. reported p97 to be a new host factor, which was an ERAD component and is involved in EV-A71 replication. The mechanism of action involves RTN3 colocalizing with 2C and p97 in EV-A71 infected cells, and thus being redistributed and concentrated in the perinuclear region. RTN3 is, therefore, redistributed from the ER membrane to the viral organelles during EV-A71 infection (Wang et al., 2017). In 2020, Su et al. (2020) revealed that multiple heat shock proteins 70 (HSP70s) were exploited by EV-A71 to participate in all phases of the viral life cycle, therein HSPA9 helped fold and stabilize the $2 \mathrm{C}$ protein, and subsequently facilitated the formation of the replication complex.

In addition, coat protein complex I (COPI) and COPII have been reported to be involved in the formation of picornavirusinduced vesicles. Wang et al. (2012b) reported that COPI, but not COPII, is required for EV-A71 replication and production, with the regulation mechanism relying upon the fact that only the $2 \mathrm{C}$ protein can interact with the coatomer subunit of COPI. More recently, TRIM4, exportin2, and ARFGAP1 have been identified as novel host factors by a GST pull-down assay using proteomic analysis. These three proteins were validated as $2 \mathrm{C}$ binding partners and were demonstrated to be novel host dependency factors for EV-A71 (Li et al., 2019b). In particular, the interactions between 2C-exportin 2 and 2C-ARFGAP1 were conserved among other enteroviruses. An understanding of viral-host interactions is important for elucidation of viral pathogenesis, and might provide broad-spectrum anti-viral drug targets for enterovirus infection, so future studies will focus on the discovery of more novel host factors that interact with the $2 \mathrm{C}$ proteins. Further studies should also investigate whether these host factors are specifically or generally involved in enteroviruses infections. It is necessary to explore the extent of conservation of these host factors among other enteroviruses and even picornaviruses.

\section{EFFECTS ON THE HOST IMMUNE RESPONSE}

The innate immune system is the first line of human defense against foreign and dangerous materials or pathogens, and is linked to the activation and programming of adaptive immune responses (Takeuchi and Akira, 2009). The innate immune system is equipped with pattern recognition receptors (PRRs) to detect invading pathogens (Jin et al., 2018). There are three pathways by which the innate immune system detects and recognizes invading microorganisms (Turvey and Broide, 2010). First, the PRRs recognize foreign pathogens as "microbial non-self" by the detection of pathogen-associated molecular patterns (PAMPs). Second, PRRs can recognize and respond to common metabolic consequences of infection and inflammation with danger-associated molecular patterns (DAMPs; Bianchi, 2007). Lastly, the "missing self" molecules derived from normal healthy cells but not infected cells or microbes can also be recognized by innate immune receptors (Jin et al., 2018). Retinoic acid-inducible gene I (RIG-I)-like receptors (RLRs), Toll-like receptors (TLRs), and NOD-like receptors (NLRs) are the three main PRRs responsible for inducing the production of type I IFNs and inflammatory cytokines, which are important innate immune regulators during viral infections 
(Akira et al., 2006). To date, the RLRs family has been shown to consist of three members: RIG-I, melanoma differentiationassociated protein 5 (MDA5), and laboratory of genetics and physiology 2 (LGP2; Chen and Ling, 2019). Both RIG-I and MDA5 are intracellular dsRNA sensors. The differences between them are that RIG-I recognizes short double-stranded RNA (dsRNA) or 5' -triphosphate single-stranded RNA (ssRNA) with poly(U/A) motifs during RNA virus infection, whereas MDA5 senses long dsRNA $>2 \mathrm{~kb}$ or viral RNA lacking 2-O-methylation (Hornung et al., 2006; Kato et al., 2008; Zust et al., 2011; Goubau et al., 2014). RIG-I and MDA5 both contain two $\mathrm{N}$-terminal caspase recruitment domains (CARDs), a central $\mathrm{DExD} / \mathrm{H}$ box ATPase/helicase domain, and a C-terminal regulatory/repression domain (Li et al., 2016a). After recognizing viral infection, the activated RIG-I and MDA5 release their CARD domain to interact with the same domain of the mitochondrial anti-viral signaling (MAVS, also known as IPS-1, VISA, or CARDIF) protein. The transcription factors IFN regulatory factor 3 (IRF3) and NF- $\kappa B$ are activated by interaction with activated MAVS (Kang et al., 2002; Yoneyama and Fujita, 2008; Fitzgerald et al., 2014). Activated IRF3 and NF- $\kappa \mathrm{B}$ subsequently translocate to the nucleus and stimulate the expression of type I IFNs, interferon-stimulated genes (ISG), and inflammatory cytokines (Sato et al., 1998;
Yoneyama et al., 1998). Thus, RIG-I and MDA5 play important roles in the activation of the IFN signaling pathway.

Many viruses have evolved mechanisms to regulate the $\mathrm{NF}-\kappa \mathrm{B}$ pathway for viral replication and cell survival to evade host immune responses. As shown in Figure 4, Zheng et al. (2011) found that the phosphorylation of IKK $\beta$ is inhibited by EV-A71 2C protein, thereby blocking TNF- $\alpha$-mediated NF- $\kappa B$ activation. Specifically, $2 \mathrm{C}$ can directly bind to the $\mathrm{KD}$ domain of IKK $\beta$ through the $1-125$ aa of the $\mathrm{N}$-terminal to inhibit IKK $\beta$ phosphorylation (Zheng et al., 2011). Further research by Zheng et al. indicated that EV-A71 2C interacts with protein phosphatase 1 (PP1), recruits PP1 to $\mathrm{IKK} \beta$, and finally forms a $2 \mathrm{C}$-PP1-IKK $\beta$ complex to inhibit IKK $\beta$ phosphorylation and the subsequent NF- $\mathrm{KB}$ signaling pathway. CV-A16 $2 \mathrm{C}, \mathrm{CV}-\mathrm{B} 3$ $2 \mathrm{C}$, and $\mathrm{PV} 2 \mathrm{C}$ also possess the ability to suppress $\mathrm{IKK} \beta$ phosphorylation in the same way as EV-A71 2C (Li et al., 2016 b). The $2 \mathrm{C}$ protein is associated with both virus replication and innate immune evasion. Du et al. (2015) reported two different pathways by which NF- $\kappa$ B activation is suppressed by EV-A71 2C protein. One was RelA (p65)/p50, the predominant form of NF- $\kappa B$; its dimerization is inhibited by the 105-125 and 126-203 aa of EV-A71 2C, competing to interact with the IPT domain of $\mathrm{p} 65$, thus releasing the association between p65 and p50. Another mechanism is the suppression of NF- $\kappa B$

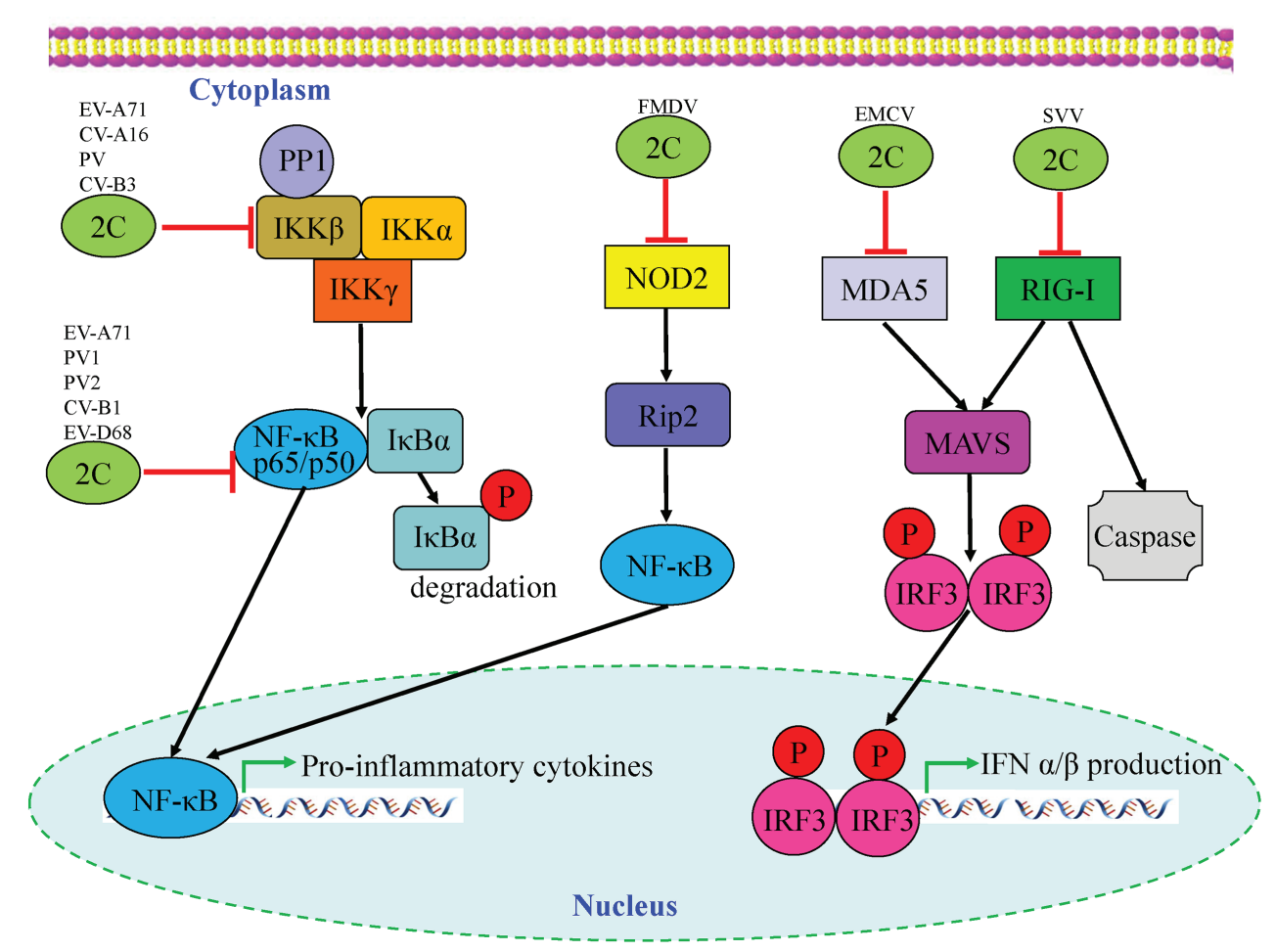

FIGURE 4 | Interactions between picornavirus 2C protein and the NF-kB and retinoic acid-inducible gene I (RIG-I)-like receptor (RLR) pathways. Enterovirus 2C proteins are mainly involved in downregulation of pro-inflammatory cytokines by targeting the NF- $\mathrm{BB}$ pathway, while foot-and-mouth disease virus (FMDV) $2 \mathrm{C}$ regulates the corresponding pathway by suppressing the expression of NOD-2. Two picornavirus $2 \mathrm{C}$ proteins, including encephalomyocarditis virus (EMCV) and seneca valley virus (SW), are shown to target the MDA5 and RIG-I of the RLR pathway which may cause downstream mediators to counteract antiviral innate immunity. 
activation by the 1-104 and 105-121 aa of $2 \mathrm{C}$ through association with IKK $\beta$ (Figure 4; Table 2).

To date, there have been relatively few studies on enterovirus 2C proteins in the RLR and NLR pathways. However, the non-structural 2C proteins of other RNA viruses in the Picornaviridae family have been reported to be associated with the RLR pathway. As shown in Figure 4, the encephalomyocarditis virus (EMCV, Cardiovirus genus) $2 \mathrm{C}$ protein was reported to interact with MDA5 to suppress the induction of IFN- $\beta$ expression (Li et al., 2019a). The suppression of IFN- $\beta$ promoter activity and the ability to interact with MDA5 were reduced or lost by the V26 mutation of the EMCV 2C protein. In addition, V26A and K25-3A mutants of EMCV 2C abolished the effect of reducing the phosphorylation of IRF3. Wen et al. (2019) revealed that the $2 \mathrm{C}$ and $3 \mathrm{C}$ proteins of the seneca valley virus (SVV, Senecavirus genus) could weaken the host innate immune system by the degradation of RIG-I through the caspase signaling pathway. Recently, NLRs have been demonstrated to play vital roles in the host immune response during viral infection (Lupfer and Kanneganti, 2013). Liu et al. demonstrated that as well as $2 \mathrm{~B}$ and $3 \mathrm{C}$, the foot-andmouth disease virus (FMDV, Aphthovirus genus) 2C protein can also reduce the expression of the protein levels of NOD2, a novel cytoplasmic viral pattern recognition receptor identified in 2009 (Liu et al., 2019). However, the mechanism of reduction of NOD2 by FMDV 2C does not involve proteasomes, lysosomes, caspases, cellular apoptosis, or cleavage of eIF4G. The 116-260 truncation of FMDV 2C was demonstrated to play a vital role in interactions with NOD2, but a reduction of NOD2 expression was not induced by truncated $2 \mathrm{C}$ mutants (Figure 4; Table 2). In conclusion, host cells have developed multiple strategies against viral infections; however, viruses have evolved many antagonistic mechanisms to escape the host innate immune response. These studies have led to the identification of the critical roles of $2 \mathrm{C}$ proteins as immunomodulatory property regulators. Further studies will not only investigate the host immune response activation suppression by $2 \mathrm{C}$ proteins of the main circulating enteroviruses but also provide a general understanding of picornavirus $2 \mathrm{C}$ proteins, as vital mechanisms that are likely to be conserved in most of the picornaviruses.

\section{REGULATION OF HOST CELL AUTOPHAGY}

Autophagy is a conserved intracellular process which acts to remove unnecessary or dysfunctional cytoplasmic proteins and damaged or obsolete organelles by delivering them to lysosomes for degradation and recycling (Klionsky, 2005; Esclatine et al., 2009). Our previous study was the first to report that viral protein $2 \mathrm{C}$ of CV-A6 contributed to the pathogenicity of CV-A6 by inducing cell death through the autophagy pathway (Wang et al., 2018), but the mechanism underlying this phenomenon needs to be further elucidated (Table 2).

In 2009, Huang et al. (2009) reported that EV-A71 infection can induce autophagy and increase viral replication both in vitro and in vivo. EV-A71 $2 \mathrm{C}$ was identified to colocalize with microtubule-associated protein 1 light chain 3 (LC3) and mannose-6-phosphate receptor (MPR), indicating the potential for amphisome formation and autophagy induction (Lee et al., 2014). Recently, Li et al. (2018c) reported that

TABLE 2 | Mechanism in suppressing the production of IFNs, inhibiting virus replication, and inducing autophagy by picornavirus $2 \mathrm{C}$ proteins.

\begin{tabular}{|c|c|c|c|c|c|}
\hline Protein & Genus & Species & Functions & Mechanism & References \\
\hline $2 \mathrm{C}$ & Enterovirus & $\begin{array}{l}\text { EV-A71; EV-A71, CV- } \\
\text { A16, PV, CV-B3; EV- } \\
\text { A71, PV1, PV2, CV-B1, } \\
\text { EV-D68 }\end{array}$ & Inhibits NF-кB signaling pathway & $\begin{array}{l}\text { By interaction with IKK } \beta \text {; by interaction with } \\
\text { IKK } \beta \text { and PP1; suppressing p65/p50 } \\
\text { dimerization by competing p } 65 \text { IPT domain } \\
\text { and by targeting } \operatorname{Rel}(\mathrm{A}) \text { and IKK } \beta\end{array}$ & $\begin{array}{l}\text { Zheng et al., 2011; D } \\
\text { et al., 2015; Li et al., } \\
2016 b\end{array}$ \\
\hline $2 \mathrm{C}$ & Aphthovirus & FMDV & $\begin{array}{l}\text { Antagonizes NOD2-mediated } \\
\text { IFN- } \beta \text { and NF- } \kappa \text { B signaling } \\
\text { pathways }\end{array}$ & $\begin{array}{l}\text { By interaction between NOD2 and the } \\
\text { ATPase domain of } 2 \mathrm{C}\end{array}$ & Liu et al., 2019 \\
\hline $2 \mathrm{C}$ & Senecavirus & SW & Inhibit the production of IFN- $\beta$ & By inducing the degradation of RIG-I & Wen et al., 2019 \\
\hline $2 \mathrm{C}$ & Cardiovirus & EMCV & Suppress IFN- $\beta$ signaling pathway & By interaction with MDA5 & Li et al., 2019a \\
\hline $2 \mathrm{C}$ & Enterovirus & EV-A71 & Viral replication & By interaction with COPI & Wang et al., 2012b \\
\hline $2 \mathrm{C}$ & Enterovirus & EV-A71, CV-A16, PV & Viral replication & By interaction with RTN3 & Tang et al., 2007 \\
\hline $2 \mathrm{C}$ & Enterovirus & $\begin{array}{l}\text { EV-A71, PV1, PV2, } \\
\text { CV-B1, EV-D68 }\end{array}$ & Viral replication & $\begin{array}{l}\text { By interaction with TRIM4, exportin2, and } \\
\text { ARFGAP1 }\end{array}$ & Li et al., 2019b \\
\hline $2 \mathrm{C}$ & Aphthovirus & FMDV & Viral replication & By interaction with Beclin1 & Gladue et al., 2012 \\
\hline $2 \mathrm{C}$ & Enterovirus & PV & $\begin{array}{l}\text { Negatively regulate } 3 \mathrm{C} \text { protease } \\
\text { activity }\end{array}$ & By interaction with 3C & Banerjee et al., 2004 \\
\hline 2BC & Enterovirus & EV-A71 & Autophagy & By interaction with SNARE proteins & Lai et al., 2017 \\
\hline $2 \mathrm{C}$ & Enterovirus & EV-A71 & Autophagy & By colocalize with LC3 and MPR & Lee et al., 2014 \\
\hline $2 \mathrm{C}$ & Enterovirus & $\begin{array}{l}\text { EV-A71, CV-A16, CV- } \\
\text { A6, EV-D68 }\end{array}$ & Autophagy & By induce $A 3 G$ degradation & Li et al., $2018 \mathrm{c}$ \\
\hline $2 \mathrm{C}$ & Enterovirus & CV-A6 & Autophagy & Unclear & Wang et al., 2018 \\
\hline $2 \mathrm{C}$ & Enterovirus & CV-A16 & Autophagy & $\begin{array}{l}\text { By increase IRGM promoter activation and } \\
\text { enhance IRGM protein expression }\end{array}$ & Shi et al., 2015 \\
\hline $2 \mathrm{C}$ & Cardiovirus & EMCV & Autophagy & $\begin{array}{l}\text { Activate ER stress molecules and regulate } \\
\text { proteins expression of UPR pathway }\end{array}$ & Hou et al., 2014 \\
\hline
\end{tabular}


the EV-A71 2C protein could overcome host restriction factor APOBEC3G (A3G) suppression through the autophagylysosome pathway, whose functions are conserved among EV-D68, CV-A6, and CV-A16. The autophagosome-lysosome fusion process is regulated by a family of $\mathrm{N}$-ethylmaleimidesensitive factor attachment receptor (SNARE) proteins (Wang et al., 2016). SNARE fusion bundles require four $\alpha$ helices to function, including Qa, Qb, Qc, and R (Rizo, 2003). Syntaxin-17 (STX17) is the Qa SNARE on the completed autophagosome, which can coordinate its fusion with other vesicles (Itakura et al., 2012). Synaptosome-associated protein 29 (SNAP29) is a cytosolic Qbc SNARE that can donate its helices to the formation of a fusion bundle by interaction with STX17 (Morelli et al., 2014). The non-structural protein $2 \mathrm{BC}$ of EV-A71, which is a precursor protein of $2 \mathrm{~B}$ and $2 \mathrm{C}$, has been reported to trigger the formation of autolysosomes, which facilitate virus replication by interacting with both SNARE proteins STX17 and SNAP29 (Table 2; Lai et al., 2017). Recently, Shi et al. (2015) found that the $2 \mathrm{C}$ protein of CV-A16 is sufficient to induce incomplete autophagy. The immunity-related GTPase family M (IRGM) promoter activity and the protein expression levels are enhanced by the expression of CV-A16 2C, and subsequently induce autophagy. Non-structural protein $2 \mathrm{C}$ of EMCV is involved in triggering autophagy induced by EMCV infection in BHK-21 cells (Hou et al., 2014). Autophagy is induced by EMCV 2C through activation of the ER stress pathway by regulating the expression of PERK and ATF6 $\alpha$, which are involved in the UPR pathway. The $2 \mathrm{C}$ protein of FMDV is co-localized with LC3, an autophagosome marker, in FMDV-infected cells, indicating the potential for induction of autophagy by FMDV 2C (O'Donnell et al., 2011). The $2 \mathrm{C}$ protein of FMDV binds to Beclin1, a central regulator of the autophagy pathway, thereby repressing the fusion of lysosomes to autophagosomes and subsequent viral survival (Table 2; Gladue et al., 2012). The relationship between the viral $2 \mathrm{C}$ protein and host cell autophagy-related proteins needs to be further studied to better evaluate the role of the $2 \mathrm{C}$ protein in virus infection.

\section{EFFECT OF ANTI-VIRAL DRUGS ON THE 2C PROTEIN}

Within the Enterovirus genus, there are two effective vaccines for two human pathogens, PV and EV-A71. However, the current total of human enteroviruses exceeds several hundred serotypes, and the development of vaccines against all enteroviruses is unlikely to be achieved. Severe, life-threatening illness can occur, especially in young children, due to enterovirus infection. Thus, there is an urgent need for the development of new anti-viral drugs against different types of enteroviruses (Ulferts et al., 2016).

As $2 \mathrm{C}$ is a highly conserved viral non-structural protein, possesses ATPase activity and is functionally indispensable, it is a promising target for drug development involving broadspectrum enterovirus inhibitors (Bauer et al., 2017). To date, several anti-viral inhibitors which target the $2 \mathrm{C}$ protein have been identified, including guanidine hydrochloride ( $\mathrm{GuHCl}$; Pfister and Wimmer, 1999; Sadeghipour et al., 2012), HBB (Hadaschik et al., 1999), MRL-1237 (Shimizu et al., 2000), and TBZE-029 (De Palma et al., 2008a). In addition, several other compounds, such as metrifudil (Arita et al., 2008), $N^{6}$ benzyladenosine (Arita et al., 2008), quinoline analogues (Musharrafieh et al., 2019), dibucaine derivatives (Tang et al., 2020), fluoxetine analogues (Manganaro et al., 2020), R523062 (Ma et al., 2020), and viperin (Wei et al., 2018), which also target the enterovirus $2 \mathrm{C}$ protein, are summarized in Table 3.

\section{Guanidine Hydrochloride}

Of these drugs, $\mathrm{GuHCl}$ is the most extensively studied (Rightsel et al., 1961; Loddo et al., 1962). GuHCl is an FDA-approved small compound drug that has been used for the treatment of the autoimmune disorder disease Lambert-Eaton myasthenic syndrome (Lambert, 1966). GuHCl can inhibit the replication of several picornaviruses, including $\mathrm{PV}$, coxsackieviruses, echoviruses, and FMDV, but not HAV (De Palma et al., 2008b). Early in vitro studies have shown that the initiation of viral RNA synthesis is inhibited by $\mathrm{GuHCl}$ (Tershak, 1982). It has been shown that $\mathrm{GuHCl}$ suppresses $2 \mathrm{C}$ function, which is required for the initiation of negative- but not positive-strand RNA synthesis, and RNA chain elongation of PV (Barton and Flanegan, 1997). Several studies into the resistance and/or dependence of PV and FMDV to $\mathrm{GuHCl}$ attributed this resistance to the 2C protein (Saunders et al., 1985; Pincus et al., 1986, 1987; Baltera and Tershak, 1989; Tolskaya et al., 1994). The resistance of $\mathrm{PV}$ to $\mathrm{GuHCl}$ was attributed primarily to mutations at positions 179 and 187 of $2 \mathrm{C}$ (Pincus et al., 1986; Tolskaya et al., 1994). Pfister et al. (2000) found that ATP hydrolysis activity can be inhibited by $\mathrm{GuHCl}$ at millimolar concentrations, and the resistance and dependence of $\mathrm{GuHCl}$ were also attributed to 2C (Pfister and Wimmer, 1999).

It has long been considered that the helicase of viruses is a potential target for anti-viral drug development due to its importance in viral RNA replication (Kwong et al., 2005). Previous studies have demonstrated that the ATPase activity of PV 2C could be inhibited by GuHCl (Pfister and Wimmer, 1999). Similarly, serial studies have reported that $\mathrm{GuHCl}$ can inhibit the NTPase and helicase activities of several helicases, including the $2 \mathrm{C}$ protein of EV-A71, NS3 protein of human norovirus, and VP35 protein of Ebola virus (EBOV), as well as inhibit the RNA replication of enterovirus, norovirus, and EBOV (Xia et al., 2015; Li et al., 2018b; Shu et al., 2019). Guanidines are universally present in the environment and may bind to the surface of viral RNA remodeling proteins to change their conformations, electrostatic states, and protein-protein or protein-RNA interactions, ultimately inhibiting the corresponding RNA remodeling activities (Shu et al., 2019). Because toxicity concerns of $\mathrm{GuHCl}$ may prevent its clinical use, recent drug development for guanidine derivatives have identified several potential anti-viral drugs against HCV, human immunodeficiency virus (HIV), and flaviviruses (Frick, 2007; Saczewski and Balewski, 2009, 2013; Lindquist and Stangel, 2011). 
TABLE 3 | Literature reported anti-viral drugs targeting enterovirus 2C proteins.

\begin{tabular}{|c|c|c|c|}
\hline Drugs & Species & Drug-resistant mutations & References \\
\hline $\mathrm{GuHCl}$ & PV; PV, CV-B3 & $\begin{array}{l}\text { I142V, N179G, M187L; A143G, S225T, I227M, } \\
\text { A233T/S; A224V, I227V, A229V }\end{array}$ & $\begin{array}{l}\text { Pincus et al., 1986; Tolskaya et al., 1994; } \\
\text { De Palma et al., 2008a }\end{array}$ \\
\hline Fluoxetine & CV-B3; CV-B3, EV-D68 & C179F, F190L; A224V, I227V, A229V & Ulferts et al., 2013; Bauer et al., 2019 \\
\hline Fluoxetine analogues $2 \mathrm{~b}$ & CV-B3, EV-D68 & A224V, I227V, A229V, C179F & Manganaro et al., 2020 \\
\hline TBZE-029 & CV-B3 & A224V, I227V, A229V & De Palma et al., 2008a \\
\hline HBB & CV-B3 & A224V, I227V, A229V & De Palma et al., 2008a \\
\hline MRL-1237 & PV; CV-B3 & I120V, F164Y; A224V, I227V, A229V & Shimizu et al., 2000; De Palma et al., 2008a \\
\hline Pirlindole & CV-B3 & A224V, I227V, A229V & Ulferts et al., 2016 \\
\hline Dibucaine & CV-B3 & A224V, I227V, A229V & Ulferts et al., 2016 \\
\hline Dibucaine derivatives $6 \mathrm{i}$ & EV-A71 & ND & Tang et al., 2020 \\
\hline Zuclopenthixol & CV-B3 & A224V, I227V, A229V & Ulferts et al., 2016 \\
\hline Metrifudil & EV-A71 & E325G & Arita et al., 2008 \\
\hline$N^{6}$-benzyladenosine & EV-A71 & H118Y, I324M & Arita et al., 2008 \\
\hline Quinoline analogues 10a, 12a, 12c & EV-D68 & ND & Musharrafieh et al., 2019 \\
\hline R523062 & EV-D68 & $1227 \mathrm{~L}$ & Ma et al., 2020 \\
\hline Viperin & EV-A71 & ND & Wei et al., 2018 \\
\hline
\end{tabular}

ND, not determined.

\section{Drug Repurposing}

Recently, drug repurposing has become of increasing interest, as the pharmacological and toxicological information related to many drugs are already available, and when a repurposed drug is used at a similar dosage as it was in its original application, it may directly enter phase II clinical trials, thereby saving development cost and time. To date, fluoxetine, pirlindole, dibucaine, and zuclopenthixol, all FDA-approved drugs, have been identified using drug repurposing screens, as targeting $2 \mathrm{C}$ proteins and inhibiting the replication of enterovirus species B and D members (Ulferts et al., 2013, 2016).

Fluoxetine, which is a selective serotonin reuptake inhibitor, selectively suppresses the replication of EV-B and EV-D, but not EV-A, EV-C, or rhinovirus A or B (RV-A or -B; Ulferts et al., 2013). TBZE-029, which is also a $2 \mathrm{C}$ targeting compound, could inhibit the growth of EV-B and EV-D, but not EV-A or EV-C (Ulferts et al., 2013). In 2019, Bauer et al. (2019) reported that the $S$-enantiomer of fluoxetine inhibits enterovirus replication by directly binding to the $2 \mathrm{C}$ protein of $\mathrm{CV}-\mathrm{B} 3$. A substitution at positions A224, I227, and A229 of the 2C protein, which are located in the short stretch of amino acids 224AGSINA229 and the C-terminal of ATPase motif C, could confer resistance to fluoxetine (Ulferts et al., 2013). This 224AGSINA229 motif is conserved between EV-B (CV-B3) and EV-D (EV-D68) but not in other species of enteroviruses (Bauer et al., 2019). The differences mean that some of these mutations can confer resistance to fluoxetine, indicating the vital role of the substitution sensitivity of these viruses to this inhibitor (Ulferts et al., 2013). A mutation in the 224AGSINA229 loop not only confers resistance to fluoxetine but also to several other compounds, including TBZE-029, HBB, MRL-1237, and GuHCl (De Palma et al., 2008a; Ulferts et al., 2013). The authors built a homology model of CV-B3 $2 \mathrm{C}$ based on the crystal structure of the published EV-A71 2C (Guan et al., 2017) to investigate the mechanism by which fluoxetine binds to CV-B3 2C (Bauer et al., 2019). Unfortunately, the $2 \mathrm{C}$ mutations at the bottom (positions I227V, C179F, and F190L) and on the borders (positions V187M and D245N) of the predicted pocket against $(S)$-fluoxetine binding activities were completely opposite, so the entrance sites that fluoxetine used to the hydrophobic cavity of $2 \mathrm{C}$ could not be confirmed (Bauer et al., 2019).

Recently, Ulferts et al. (2016) identified pirlindole as a novel inhibitor by screening FDA-approved drugs against CV-B3. They found that EV-B and EV-D could both be suppressed by pirlindole and dibucaine, and dibucaine could also inhibit EV-A, but none of these compounds could inhibit EV-C or RVs. All of these compounds exert an inhibitory effect by acting at the stage of genome replication. Further studies revealed that $\mathrm{A} 224 \mathrm{~V}, \mathrm{I} 227 \mathrm{~V}$, and $\mathrm{A} 229 \mathrm{~V}$ mutations of $2 \mathrm{C}$ provide resistance to pirlindole, dibucaine, and zuclopenthixol, a finding which was consistent with the effects of $\mathrm{GuHCl}$ and fluoxetine in anti-enteroviral treatment. However, formoterol, which could inhibit all tested enteroviruses and RVs, does not target 2C, and its mechanism of action needs to be further elucidated (Ulferts et al., 2016).

\section{Outlook}

Collectively, future anti-viral drug development against enterovirus infection will focus on the RNA remodeling activity of $2 \mathrm{C}$ protein, to modify and screen various guanidine derivatives with better inhibitory effects and lower toxicity. Fluoxetine, which was once used to treat major depression and anxiety disorders, has more recently been used as an effective inhibitor for immunocompromised children with chronic enterovirus encephalitis (Gofshteyn et al., 2016), demonstrating its potential for clinical use as an enterovirus $2 \mathrm{C}$ inhibitor. So far, these $2 \mathrm{C}$ inhibitors have not been approved for clinical application in the treatment of enteroviral infections. Hence, we need more crystallographic data on the types of enterovirus 2C proteins, to clarify the underlying mechanisms of the inhibitors' efficacy, drug resistance, and exact binding style, and to facilitate the rational design of fluoxetine-derived and developing novel broad-spectrum enterovirus drugs. 


\section{CONCLUSION AND FUTURE PERSPECTIVES}

Enteroviruses are the main causes of HFMD, with EV-A71, CV-A16, CV-A6, and CV-A10 being the main circulating pathogens of HFMD, especially in the Asia-Pacific region. The non-structural $2 \mathrm{C}$ protein is the most highly conserved of the enteroviral proteins but is still poorly understood. In this review, we focused on the current understanding of the structure and multi-functionality of the $2 \mathrm{C}$ proteins of enteroviruses, and the different roles of $2 \mathrm{C}$ proteins and host innate immunity. In the past two decades, PV 2C has been the most-studied non-structural $2 \mathrm{C}$ protein. Previous studies have demonstrated that the $\mathrm{PV} 2 \mathrm{C}$ protein possesses multiple activities in the viral life cycle (Table 1). The $2 \mathrm{C}$ proteins of EV-A71 and CV-A16 were first revealed to have ATP-dependent RNA helicase and ATP-independent chaperoning activities, which are critical for viral RNA replication (Xia et al., 2015). In the present review, we summarized and discussed the current understanding of the relationships between structure and function of the enterovirus $2 \mathrm{C}$ proteins, especially the key mutations and motifs involved in viral infection and replication (Figure 2). Future studies will focus on the determination of additional crystal structures of enterovirus $2 \mathrm{C}$ proteins, data which will help us to elucidate the detailed mechanism of $2 \mathrm{C}$ protein involvement in virus replication and packaging.

In this review, we summarized novel host factors such as RTN3, COPI, TRIM4, exportin2, and ARFGAP1, which have been demonstrated to interact with enterovirus $2 \mathrm{C}$ proteins to contribute to viral replication (Figure 3; Table 2). Further studies will identify additional host factors that interact with 2C, help us to better understand enterovirus biology, and provide new targets for the development of anti-viral therapy. It is important to investigate the conservation of these host factors among other enteroviruses and even picornaviruses.

The innate immune system is the first line of defense against viral infections, and thus triggers adaptive immunity, which plays vital roles in the fight against viral infections, especially the induction of type I IFN response. Several studies have reported that picornavirus $2 \mathrm{C}$ proteins participate in host innate immunity by associating with the NF-KB, MDA5, RIG-I, NOD2, and IFN signaling pathways (Figure 4; Table 2), which provide the mechanisms for evasion of the innate immune response

\section{REFERENCES}

Akira, S., Uematsu, S., and Takeuchi, O. (2006). Pathogen recognition and innate immunity. Cell 124, 783-801. doi: 10.1016/j.cell.2006.02.015

Aldabe, R., and Carrasco, L. (1995). Induction of membrane proliferation by poliovirus proteins 2C and 2BC. Biochem. Biophys. Res. Commun. 206, 64-76. doi: 10.1006/bbrc.1995.1010

Arita, M., Wakita, T., and Shimizu, H. (2008). Characterization of pharmacologically active compounds that inhibit poliovirus and enterovirus 71 infectivity. J. Gen. Virol. 89, 2518-2530. doi: 10.1099/vir.0.2008/002915-0

Arita, M., Wakita, T., and Shimizu, H. (2012). Valosin-containing protein (VCP/ p97) is required for poliovirus replication and is involved in cellular protein secretion pathway in poliovirus infection. J. Virol. 86, 5541-5553. doi: 10.1128/ JVI.00114-12 during viral infection. Further studies will focus on the detailed mechanisms by which $2 \mathrm{C}$ proteins target and regulate the NF- $\mathrm{KB}$ pathway and the three major classes of PRRs, which will ultimately lead to clarification of the interplay between PRRs and the innate immune system.

Currently, although there has been successful use of a vaccine against EV-A71, a novel vaccine against all enteroviruses or multiple circulating causative pathogens is unavailable. Thus, there is an urgent need for novel anti-viral drugs, especially broad-spectrum anti-viral drugs, to treat multiple enterovirus infections. The broad-spectrum anti-enteroviral fluoxetine is considered as the most promising $2 \mathrm{C}$ inhibitor, but detailed mode-of-action studies are still missing, as the crystal structure of the $2 \mathrm{C}$ protein, which is derived from fluoxetine-sensitive enteroviruses, has still not been solved (Table 3). Recently, the crystal structures of EV-A71 2C and PV 2C have been resolved (Guan et al., 2017, 2018). However, the crystal structures of other enterovirus $2 \mathrm{C}$ proteins, especially the main circulating pathogens such as CV-A16, CV-A6, and CV-A10, have not been determined. Future studies will focus on the determination of the crystal structure of different types of enterovirus $2 \mathrm{C}$ proteins and screening of broader anti-viral drugs, which will help us to elucidate the pathogenesis of enteroviral infections, and facilitate the development and application of $2 \mathrm{C}$ inhibitors for clinical treatment for enteroviral infections.

\section{AUTHOR CONTRIBUTIONS}

S-HW is the first author of this article and wrote the manuscript. $\mathrm{KW}$ and $\mathrm{KZ}$ had made contributions to this article. S-CH and JD had discussed and revised this article. All authors contributed to the article and approved the submitted version.

\section{FUNDING}

This study was supported by funding from the National Natural Science Foundation of China (no. 81902049), the Science and Technology Department of Jilin Province (20200201525JC), the Fundamental Research Funds for the Central Universities (2017TD-08), and the Key Laboratory of Molecular Virology, Jilin Province (20102209).
Asare, E., Mugavero, J., Jiang, P., Wimmer, E., and Paul, A. V. (2016). A single amino acid substitution in poliovirus nonstructural protein 2CATPase causes conditional defects in encapsidation and uncoating. J. Virol. 90, 6174-6186. doi: 10.1128/JVI.02877-15

Baltera, R. F. Jr., and Tershak, D. R. (1989). Guanidine-resistant mutants of poliovirus have distinct mutations in peptide 2C. J. Virol. 63, 4441-4444. doi: 10.1128/JVI.63.10.4441-4444.1989

Banerjee, R., and Dasgupta, A. (2001). Interaction of picornavirus 2C polypeptide with the viral negative-strand RNA. J. Gen. Virol. 82, 2621-2627. doi: 10.1099/0022-1317-82-11-2621

Banerjee, R., Echeverri, A., and Dasgupta, A. (1997). Poliovirus-encoded 2C polypeptide specifically binds to the $3^{\prime}$-terminal sequences of viral negativestrand RNA. J. Virol. 71, 9570-9578. doi: 10.1128/JVI.71.12.9570-95 78.1997 
Banerjee, R., Tsai, W., Kim, W., and Dasgupta, A. (2001). Interaction of poliovirusencoded $2 \mathrm{C} / 2 \mathrm{BC}$ polypeptides with the $3^{\prime}$ terminus negative-strand cloverleaf requires an intact stem-loop b. Virology 280, 41-51. doi: 10.1006/viro.2000.0770

Banerjee, R., Weidman, M. K., Echeverri, A., Kundu, P., and Dasgupta, A. (2004). Regulation of poliovirus 3C protease by the 2C polypeptide. J. Virol. 78, 9243-9256. doi: 10.1128/JVI.78.17.9243-9256.2004

Barton, D. J., and Flanegan, J. B. (1997). Synchronous replication of poliovirus RNA: initiation of negative-strand RNA synthesis requires the guanidineinhibited activity of protein 2C. J. Virol. 71, 8482-8489. doi: 10.1128/ JVI.71.11.8482-8489.1997

Bauer, L., Lyoo, H., van der Schaar, H. M., Strating, J. R., and van Kuppeveld, F. J. (2017). Direct-acting antivirals and host-targeting strategies to combat enterovirus infections. Curr. Opin. Virol. 24, 1-8. doi: 10.1016/j.coviro.2017.03.009

Bauer, L., Manganaro, R., Zonsics, B., Strating, J., El Kazzi, P., Lorenzo Lopez, M., et al. (2019). Fluoxetine inhibits enterovirus replication by targeting the viral 2C protein in a stereospecific manner. ACS Infect. Dis. 5, 1609-1623. doi: 10.1021/acsinfecdis.9b00179

Bianchi, M. E. (2007). DAMPs, PAMPs and alarmins: all we need to know about danger. J. Leukoc. Biol. 81, 1-5. doi: 10.1189/jlb.0306164

Cameron, C. E., Oh, H. S., and Moustafa, I. M. (2010). Expanding knowledge of P3 proteins in the poliovirus lifecycle. Future Microbiol. 5, 867-881. doi: $10.2217 / \mathrm{fmb} .10 .40$

Chang, L. Y., Huang, Y. C., and Lin, T. Y. (1998). Fulminant neurogenic pulmonary oedema with hand, foot, and mouth disease. Lancet 352, 367-368. doi: 10.1016/S0140-6736(98)24031-1

Chen, K. R., and Ling, P. (2019). Interplays between enterovirus A71 and the innate immune system. J. Biomed. Sci. 26:95. doi: 10.1186/s12929-019-0596-8

Cheng, Z., Yang, J., Xia, H., Qiu, Y., Wang, Z., Han, Y., et al. (2013). The nonstructural protein $2 \mathrm{C}$ of a Picorna-like virus displays nucleic acid helix destabilizing activity that can be functionally separated from its ATPase activity. J. Virol. 87, 5205-5218. doi: 10.1128/JVI.00245-13

Cho, M. W., Teterina, N., Egger, D., Bienz, K., and Ehrenfeld, E. (1994). Membrane rearrangement and vesicle induction by recombinant poliovirus 2C and 2BC in human cells. Virology 202, 129-145. doi: 10.1006/viro.1994.1329

De Palma, A. M., Heggermont, W., Lanke, K., Coutard, B., Bergmann, M., Monforte, A. M., et al. (2008a). The thiazolobenzimidazole TBZE-029 inhibits enterovirus replication by targeting a short region immediately downstream from motif C in the nonstructural protein 2C. J. Virol. 82, 4720-4730. doi: 10.1128/JVI.01338-07

De Palma, A. M., Vliegen, I., De Clercq, E., and Neyts, J. (2008b). Selective inhibitors of picornavirus replication. Med. Res. Rev. 28, 823-884. doi: 10.1002/ med. 20125

Dove, A. W., and Racaniello, V. R. (1997). Cold-adapted poliovirus mutants bypass a postentry replication block. J. Virol. 71, 4728-4735. doi: 10.1128/ JVI.71.6.4728-4735.1997

Du, H., Yin, P., Yang, X., Zhang, L., Jin, Q., and Zhu, G. (2015). Enterovirus 71 2C protein inhibits NF-kappa B activation by binding to RelA(p65). Sci. Rep. 5:14302. doi: 10.1038/srep14302

Echeverri, A. C., and Dasgupta, A. (1995). Amino terminal regions of poliovirus 2C protein mediate membrane binding. Virology 208, 540-553. doi: 10.1006/ viro. 1995.1185

Enemark, E. J., and Joshua-Tor, L. (2006). Mechanism of DNA translocation in a replicative hexameric helicase. Nature 442, 270-275. doi: 10.1038/nature04943

Esclatine, A., Chaumorcel, M., and Codogno, P. (2009). Macroautophagy signaling and regulation. Curr. Top. Microbiol. Immunol. 335, 33-70. doi: 10.1007/978-3-642-00302-8_2

Fitzgerald, M. E., Rawling, D. C., Vela, A., and Pyle, A. M. (2014). An evolving arsenal: viral RNA detection by RIG-I-like receptors. Curr. Opin. Microbiol. 20, 76-81. doi: 10.1016/j.mib.2014.05.004

Fitzgerald, K. D., and Semler, B. L. (2009). Bridging IRES elements in mRNAs to the eukaryotic translation apparatus. Biochim. Biophys. Acta 1789, 518-528. doi: 10.1016/j.bbagrm.2009.07.004

Frick, D. N. (2007). The hepatitis C virus NS3 protein: a model RNA helicase and potential drug target. Curr. Issues Mol. Biol. 9, 1-20.

Gai, D., Zhao, R., Li, D., Finkielstein, C. V., and Chen, X. S. (2004). Mechanisms of conformational change for a replicative hexameric helicase of SV40 large tumor antigen. Cell 119, 47-60. doi: 10.1016/j.cell.2004.09.017

Gladue, D. P., O’Donnell, V., Baker-Branstetter, R., Holinka, L. G., Pacheco, J. M., Fernandez-Sainz, I., et al. (2012). Foot-and-mouth disease virus nonstructural protein 2C interacts with Beclin1, modulating virus replication. J. Virol. 86, 12080-12090. doi: 10.1128/JVI.01610-12

Gofshteyn, J., Cardenas, A. M., and Bearden, D. (2016). Treatment of chronic enterovirus encephalitis with fluoxetine in a patient with X-linked agammaglobulinemia. Pediatr. Neurol. 64, 94-98. doi: 10.1016/j.pediatrneurol. 2016.06.014

Gorbalenya, A. E., and Koonin, E. V. (1989). Viral proteins containing the purine NTP-binding sequence pattern. Nucleic Acids Res. 17, 8413-8440. doi: 10.1093/nar/17.21.8413

Goubau, D., Schlee, M., Deddouche, S., Pruijssers, A. J., Zillinger, T., Goldeck, M., et al. (2014). Antiviral immunity via RIG-I-mediated recognition of RNA bearing 5'-diphosphates. Nature 514, 372-375. doi: 10.1038/nature13590

Guan, H., Tian, J., Qin, B., Wojdyla, J. A., Wang, B., Zhao, Z., et al. (2017). Crystal structure of 2C helicase from enterovirus 71. Sci. Adv. 3:e1602573. doi: $10.1126 /$ sciadv. 1602573

Guan, H., Tian, J., Zhang, C., Qin, B., and Cui, S. (2018). Crystal structure of a soluble fragment of poliovirus 2CATPase. PLoS Pathog. 14:e1007304. doi: 10.1371/journal.ppat.1007304

Hadaschik, D., Klein, M., Zimmermann, H., Eggers, H. J., and Nelsen-Salz, B. (1999). Dependence of echovirus 9 on the enterovirus RNA replication inhibitor 2-(alpha-Hydroxybenzyl)-benzimidazole maps to nonstructural protein 2C. J. Virol. 73, 10536-10539. doi: 10.1128/JVI.73.12.10536-10539.1999

He, Y. Q., Chen, L., Xu, W. B., Yang, H., Wang, H. Z., Zong, W. P., et al. (2013). Emergence, circulation, and spatiotemporal phylogenetic analysis of coxsackievirus a6- and coxsackievirus a10-associated hand, foot, and mouth disease infections from 2008 to 2012 in Shenzhen, China. J. Clin. Microbiol. 51, 3560-3566. doi: 10.1128/JCM.01231-13

Hornung, V., Ellegast, J., Kim, S., Brzozka, K., Jung, A., Kato, H., et al. (2006). 5'-Triphosphate RNA is the ligand for RIG-I. Science 314, 994-997. doi: 10.1126/science. 1132505

Hou, L., Ge, X., Xin, L., Zhou, L., Guo, X., and Yang, H. (2014). Nonstructural proteins $2 \mathrm{C}$ and $3 \mathrm{D}$ are involved in autophagy as induced by the encephalomyocarditis virus. Virol. J. 11:156. doi: 10.1186/1743-422X-11-156

Huang, S. C., Chang, C. L., Wang, P. S., Tsai, Y., and Liu, H. S. (2009). Enterovirus 71-induced autophagy detected in vitro and in vivo promotes viral replication. J. Med. Virol. 81, 1241-1252. doi: 10.1002/jmv.21502

Itakura, E., Kishi-Itakura, C., and Mizushima, N. (2012). The hairpin-type tail-anchored SNARE syntaxin 17 targets to autophagosomes for fusion with endosomes/lysosomes. Cell 151, 1256-1269. doi: 10.1016/j.cell. 2012.11.001

Ji, T., Guo, Y., Lv, L., Wang, J., Shi, Y., Yu, Q., et al. (2019). Emerging recombination of the $\mathrm{C} 2$ sub-genotype of HFMD-associated CV-A4 is persistently and extensively circulating in China. Sci. Rep. 9:13668. doi: 10.1038/s41598-019-49859-7

Jin, Y., Zhang, R., Wu, W., and Duan, G. (2018). Innate immunity evasion by enteroviruses linked to epidemic hand-foot-mouth disease. Front. Microbiol. 9:2422. doi: $10.3389 /$ fmicb.2018.02422

Kang, D. C., Gopalkrishnan, R. V., Wu, Q., Jankowsky, E., Pyle, A. M., and Fisher, P. B. (2002). mda-5: an interferon-inducible putative RNA helicase with double-stranded RNA-dependent ATPase activity and melanoma growthsuppressive properties. Proc. Natl. Acad. Sci. U. S. A. 99, 637-642. doi: 10.1073/pnas.022637199

Kato, H., Takeuchi, O., Mikamo-Satoh, E., Hirai, R., Kawai, T., Matsushita, K., et al. (2008). Length-dependent recognition of double-stranded ribonucleic acids by retinoic acid-inducible gene-I and melanoma differentiation-associated gene 5. J. Exp. Med. 205, 1601-1610. doi: 10.1084/jem.20080091

Klein, M., Hadaschik, D., Zimmermann, H., Eggers, H. J., and Nelsen-Salz, B. (2000). The picornavirus replication inhibitors HBB and guanidine in the echovirus- 9 system: the significance of viral protein 2C. J. Gen. Virol. 81, 895-901. doi: 10.1099/0022-1317-81-4-895

Klionsky, D. J. (2005). The molecular machinery of autophagy: unanswered questions. J. Cell Sci. 118, 7-18. doi: 10.1242/jcs.01620

Kwong, A. D., Rao, B. G., and Jeang, K. T. (2005). Viral and cellular RNA helicases as antiviral targets. Nat. Rev. Drug Discov. 4, 845-853. doi: 10.1038/ $\operatorname{nrd} 1853$

Lai, J. K. F., Sam, I. C., Verlhac, P., Baguet, J., Eskelinen, E. L., Faure, M., et al. (2017). 2BC non-structural protein of enterovirus A71 interacts with SNARE proteins to trigger autolysosome formation. Viruses 9:169. doi: $10.3390 / \mathrm{v} 9070169$ 
Lambert, E. H. (1966). Defects of neuromuscular transmission in syndromes other than myasthenia gravis. Ann. N. Y. Acad. Sci. 135, 367-384. doi: 10.1111/j.1749-6632.1966.tb45484.x

Lee, Y. R., Wang, P. S., Wang, J. R., and Liu, H. S. (2014). Enterovirus 71-induced autophagy increases viral replication and pathogenesis in a suckling mouse model. J. Biomed. Sci. 21:80. doi: 10.1186/s12929-014-0080-4

Li, J. P., and Baltimore, D. (1988). Isolation of poliovirus 2C mutants defective in viral RNA synthesis. J. Virol. 62, 4016-4021. doi: 10.1128/JVI.62.11.4016-4021.1988

Li, J. P., and Baltimore, D. (1990). An intragenic revertant of a poliovirus 2C mutant has an uncoating defect. J. Virol. 64, 1102-1107. doi: 10.1128/ JVI.64.3.1102-1107.1990

Li, L., Fan, H., Song, Z., Liu, X., Bai, J., and Jiang, P. (2019a). Encephalomyocarditis virus $2 \mathrm{C}$ protein antagonizes interferon-beta signaling pathway through interaction with MDA5. Antiviral Res. 161, 70-84. doi: 10.1016/j.antiviral. 2018.10.010

Li, T. F., Hosmillo, M., Schwanke, H., Shu, T., Wang, Z., Yin, L., et al. (2018b). Human Norovirus NS3 has RNA helicase and chaperoning activities. J. Virol. 92, e01606-e01617. doi: 10.1128/JVI.01606-17

Li, Y., Jian, X., Yin, P., Zhu, G., and Zhang, L. (2019b). Elucidating the host interactome of EV-A71 2C reveals viral dependency factors. Front. Microbiol. 10:636. doi: 10.3389/fmicb.2019.00636

Li, D., Lei, C., Xu, Z., Yang, F., Liu, H., Zhu, Z., et al. (2016a). Foot-andmouth disease virus non-structural protein $3 \mathrm{~A}$ inhibits the interferon-beta signaling pathway. Sci. Rep. 6:21888. doi: 10.1038/srep21888

Li, Z., Ning, S., Su, X., Liu, X., Wang, H., Liu, Y., et al. (2018c). Enterovirus 71 antagonizes the inhibition of the host intrinsic antiviral factor A3G. Nucleic Acids Res. 46, 11514-11527. doi: 10.1093/nar/gky840

Li, J., Pan, H., Wang, X., Zhu, Q., Ge, Y., Cai, J., et al. (2018a). Epidemiological surveillance of hand, foot and mouth disease in Shanghai in 2014-2016, prior to the introduction of the enterovirus 71 vaccine. Emerg. Microbes Infect. 7:37. doi: 10.1038/s41426-018-0035-Z

Li, Q., Zheng, Z., Liu, Y., Zhang, Z., Liu, Q., Meng, J., et al. (2016b). 2C proteins of enteroviruses suppress IKKbeta phosphorylation by recruiting protein phosphatase 1. J. Virol. 90, 5141-5151. doi: 10.1128/JVI.03021-15

Lindquist, S., and Stangel, M. (2011). Update on treatment options for LambertEaton myasthenic syndrome: focus on use of amifampridine. Neuropsychiatr. Dis. Treat. 7, 341-349. doi: 10.2147/NDT.S10464

Liu, Y., Wang, C., Mueller, S., Paul, A. V., Wimmer, E., and Jiang, P. (2010). Direct interaction between two viral proteins, the nonstructural protein $2 \mathrm{C}$ and the capsid protein VP3, is required for enterovirus morphogenesis. PLoS Pathog. 6:e1001066. doi: 10.1371/journal.ppat.1001066

Liu, H., Zhu, Z., Xue, Q., Yang, F., Cao, W., Zhang, K., et al. (2019). Footand-mouth disease virus antagonizes NOD2-mediated antiviral effects by inhibiting NOD2 protein expression. J. Virol. 93, e00124-e00119. doi: 10.1128/ JVI.00124-19

Loddo, B., Ferrari, W., Brotzu, G., and Spanedda, A. (1962). In vitro inhibition of infectivity of polio viruses by guanidine. Nature 193, 97-98. doi: 10.1038/193097a0

Lupfer, C., and Kanneganti, T. D. (2013). The expanding role of NLRs in antiviral immunity. Immunol. Rev. 255, 13-24. doi: 10.1111/imr.12089

Lyoo, H., Dorobantu, C. M., van der Schaar, H. M., and van Kuppeveld, F. J. M. (2017). Modulation of proteolytic polyprotein processing by coxsackievirus mutants resistant to inhibitors targeting phosphatidylinositol-4-kinase IIIbeta or oxysterol binding protein. Antiviral Res. 147, 86-90. doi: 10.1016/j. antiviral.2017.10.006

Ma, C., Hu, Y., Zhang, J., and Wang, J. (2020). Pharmacological characterization of the mechanism of action of R523062, a promising antiviral for enterovirus D68. ACS Infect. Dis. 6, 2260-2270. doi: 10.1021/acsinfecdis.0c00383

Manganaro, R., Zonsics, B., Bauer, L., Lorenzo Lopez, M., Donselaar, T., Zwaagstra, M., et al. (2020). Synthesis and antiviral effect of novel fluoxetine analogues as enterovirus 2C inhibitors. Antiviral Res. 178:104781. doi: 10.1016/j. antiviral.2020.104781

McMinn, P. C. (2002). An overview of the evolution of enterovirus 71 and its clinical and public health significance. FEMS Microbiol. Rev. 26, 91-107. doi: 10.1111/j.1574-6976.2002.tb00601.x

Mirzayan, C., and Wimmer, E. (1994). Biochemical studies on poliovirus polypeptide 2C: evidence for ATPase activity. Virology 199, 176-187. doi: 10.1006/viro.1994.1110

Morelli, E., Ginefra, P., Mastrodonato, V., Beznoussenko, G. V., Rusten, T. E., Bilder, D., et al. (2014). Multiple functions of the SNARE protein Snap29 in autophagy, endocytic, and exocytic trafficking during epithelial formation in Drosophila. Autophagy 10, 2251-2268. doi: 10.4161/15548627.2014.981913

Musharrafieh, R., Zhang, J., Tuohy, P., Kitamura, N., Bellampalli, S. S., Hu, Y., et al. (2019). Discovery of quinoline analogues as potent antivirals against enterovirus D68 (EV-D68). J. Med. Chem. 62, 4074-4090. doi: 10.1021/acs. jmedchem.9b00115

Musier-Forsyth, K. (2010). RNA remodeling by chaperones and helicases. RNA Biol. 7, 632-633. doi: 10.4161/rna.7.6.14467

Norder, H., De Palma, A. M., Selisko, B., Costenaro, L., Papageorgiou, N., Arnan, C., et al. (2011). Picornavirus non-structural proteins as targets for new anti-virals with broad activity. Antiviral Res. 89, 204-218. doi: 10.1016/j. antiviral.2010.12.007

O’Donnell, V., Pacheco, J. M., LaRocco, M., Burrage, T., Jackson, W., Rodriguez, L. L., et al. (2011). Foot-and-mouth disease virus utilizes an autophagic pathway during viral replication. Virology 410, 142-150. doi: 10.1016/j.virol.2010.10.042

Paul, A. V., Molla, A., and Wimmer, E. (1994). Studies of a putative amphipathic helix in the N-terminus of poliovirus protein 2C. Virology 199, 188-199. doi: 10.1006/viro.1994.1111

Paul, A. V., Peters, J., Mugavero, J., Yin, J., van Boom, J. H., and Wimmer, E. (2003). Biochemical and genetic studies of the VPg uridylylation reaction catalyzed by the RNA polymerase of poliovirus. J. Virol. 77, 891-904. doi: 10.1128/jvi.77.2.891-904.2003

Pfister, T., Jones, K. W., and Wimmer, E. (2000). A cysteine-rich motif in poliovirus protein 2C(ATPase) is involved in RNA replication and binds zinc in vitro. J. Virol. 74, 334-343. doi: 10.1128/jvi.74.1.334-343.2000

Pfister, T., and Wimmer, E. (1999). Characterization of the nucleoside triphosphatase activity of poliovirus protein $2 \mathrm{C}$ reveals a mechanism by which guanidine inhibits poliovirus replication. J. Biol. Chem. 274, 6992-7001. doi: $10.1074 /$ jbc. 274.11 .6992

Pincus, S. E., Diamond, D. C., Emini, E. A., and Wimmer, E. (1986). Guanidineselected mutants of poliovirus: mapping of point mutations to polypeptide 2C. J. Virol. 57, 638-646. doi: 10.1128/JVI.57.2.638-646.1986

Pincus, S. E., Rohl, H., and Wimmer, E. (1987). Guanidine-dependent mutants of poliovirus: identification of three classes with different growth requirements. Virology 157, 83-88. doi: 10.1016/0042-6822(87)90316-3

Rieder, E., Paul, A. V., Kim, D. W., van Boom, J. H., and Wimmer, E. (2000). Genetic and biochemical studies of poliovirus cis-acting replication element cre in relation to VPg uridylylation. J. Virol. 74, 10371-10380. doi: 10.1128/ jvi.74.22.10371-10380.2000

Rightsel, W. A., Dice, J. R., Mc, A. R., Timm, E. A., Mc, L. I. Jr., Dixon, G. J., et al. (1961). Antiviral effect of guanidine. Science 134, 558-559. doi: 10.1126 science.134.3478.558

Rizo, J. (2003). SNARE function revisited. Nat. Struct. Biol. 10, 417-419. doi: 10.1038/nsb0603-417

Rodriguez, P. L., and Carrasco, L. (1993). Poliovirus protein 2C has ATPase and GTPase activities. J. Biol. Chem. 268, 8105-8110.

Rodriguez, P. L., and Carrasco, L. (1995). Poliovirus protein 2C contains two regions involved in RNA binding activity. J. Biol. Chem. 270, 10105-10112. doi: $10.1074 /$ jbc.270.17.10105

Saczewski, F., and Balewski, L. (2009). Biological activities of guanidine compounds. Expert Opin. Ther. Pat. 19, 1417-1448. doi: 10.1517/13543770903216675

Saczewski, F., and Balewski, L. (2013). Biological activities of guanidine compounds, 2008-2012 update. Expert Opin. Ther. Pat. 23, 965-995. doi: 10.1517/13543776. 2013.788645

Sadeghipour, S., Bek, E. J., and McMinn, P. C. (2012). Selection and characterisation of guanidine-resistant mutants of human enterovirus 71. Virus Res. 169, 72-79. doi: 10.1016/j.virusres.2012.07.005

Sato, M., Tanaka, N., Hata, N., Oda, E., and Taniguchi, T. (1998). Involvement of the IRF family transcription factor IRF-3 in virus-induced activation of the IFN-beta gene. FEBS Lett. 425, 112-116. doi: 10.1016/s0014-5793(98)00210-5

Saunders, K., King, A. M., McCahon, D., Newman, J. W., Slade, W. R., and Forss, S. (1985). Recombination and oligonucleotide analysis of guanidineresistant foot-and-mouth disease virus mutants. J. Virol. 56, 921-929. doi: 10.1128/JVI.56.3.921-929.1985

Shi, Y., He, X., Zhu, G., Tu, H., Liu, Z., Li, W., et al. (2015). Coxsackievirus A16 elicits incomplete autophagy involving the mTOR and ERK pathways. PLoS One 10:e0122109. doi: 10.1371/journal.pone.0122109

Shih, S. R., Stollar, V., and Li, M. L. (2011). Host factors in enterovirus 71 replication. J. Virol. 85, 9658-9666. doi: 10.1128/JVI.05063-11 
Shimizu, H., Agoh, M., Agoh, Y., Yoshida, H., Yoshii, K., Yoneyama, T., et al. (2000). Mutations in the 2C region of poliovirus responsible for altered sensitivity to benzimidazole derivatives. J. Virol. 74, 4146-4154. doi: 10.1128/ jvi.74.9.4146-4154.2000

Shu, T., Gan, T., Bai, P., Wang, X., Qian, Q., Zhou, H., et al. (2019). Ebola virus VP35 has novel NTPase and helicase-like activities. Nucleic Acids Res. 47, 5837-5851. doi: 10.1093/nar/gkz340

Singleton, M. R., Dillingham, M. S., and Wigley, D. B. (2007). Structure and mechanism of helicases and nucleic acid translocases. Annu. Rev. Biochem. 76, 23-50. doi: 10.1146/annurev.biochem.76.052305.115300

Su, Y. S., Hsieh, P. Y., Li, J. S., Pao, Y. H., Chen, C. J., and Hwang, L. H. (2020). The heat shock protein 70 family of chaperones regulates all phases of the enterovirus A71 life cycle. Front. Microbiol. 11:1656. doi: 10.3389/ fmicb. 2020.01656

Suhy, D. A., Giddings, T. H. Jr., and Kirkegaard, K. (2000). Remodeling the endoplasmic reticulum by poliovirus infection and by individual viral proteins: an autophagy-like origin for virus-induced vesicles. J. Virol. 74, 8953-8965. doi: 10.1128 /jvi.74.19.8953-8965.2000

Takeuchi, O., and Akira, S. (2009). Innate immunity to virus infection. Immunol. Rev. 227, 75-86. doi: 10.1111/j.1600-065X.2008.00737.x

Tang, Q., Xu, Z., Jin, M., Shu, T., Chen, Y., Feng, L., et al. (2020). Identification of dibucaine derivatives as novel potent enterovirus $2 \mathrm{C}$ helicase inhibitors: in vitro, in vivo, and combination therapy study. Eur. J. Med. Chem. 202, 112310. doi: 10.1016/j.ejmech.2020.112310

Tang, W. F., Yang, S. Y., Wu, B. W., Jheng, J. R., Chen, Y. L., Shih, C. H., et al. (2007). Reticulon 3 binds the 2C protein of enterovirus 71 and is required for viral replication. J. Biol. Chem. 282, 5888-5898. doi: 10.1074/jbc.M611145200

Tershak, D. R. (1982). Inhibition of poliovirus polymerase by guanidine in vitro. J. Virol. 41, 313-318. doi: 10.1128/JVI.41.1.313-318.1982

Teterina, N. L., Gorbalenya, A. E., Egger, D., Bienz, K., and Ehrenfeld, E. (1997). Poliovirus 2C protein determinants of membrane binding and rearrangements in mammalian cells. J. Virol. 71, 8962-8972. doi: 10.1128/ JVI.71.12.8962-8972.1997

Teterina, N. L., Levenson, E., Rinaudo, M. S., Egger, D., Bienz, K., Gorbalenya, A. E., et al. (2006). Evidence for functional protein interactions required for poliovirus RNA replication. J. Virol. 80, 5327-5337. doi: 10.1128/JVI.02684-05

Tolskaya, E. A., Romanova, L. I., Kolesnikova, M. S., Gmyl, A. P., Gorbalenya, A. E., and Agol, V. I. (1994). Genetic studies on the poliovirus 2C protein, an NTPase. A plausible mechanism of guanidine effect on the $2 \mathrm{C}$ function and evidence for the importance of 2C oligomerization. J. Mol. Biol. 236, 1310-1323. doi: 10.1016/0022-2836(94)90060-4

Turvey, S. E., and Broide, D. H. (2010). Innate immunity. J. Allergy Clin. Immunol. 125, S24-S32. doi: 10.1016/j.jaci.2009.07.016

Ulferts, R., de Boer, S. M., van der Linden, L., Bauer, L., Lyoo, H. R., Mate, M. J., et al. (2016). Screening of a library of FDA-approved drugs identifies several enterovirus replication inhibitors that target viral protein 2C. Antimicrob. Agents Chemother. 60, 2627-2638. doi: 10.1128/AAC.02182-15

Ulferts, R., van der Linden, L., Thibaut, H. J., Lanke, K. H., Leyssen, P., Coutard, B., et al. (2013). Selective serotonin reuptake inhibitor fluoxetine inhibits replication of human enteroviruses B and D by targeting viral protein 2C. Antimicrob. Agents Chemother. 57, 1952-1956. doi: 10.1128/AAC.02084-12

Vance, L. M., Moscufo, N., Chow, M., and Heinz, B. A. (1997). Poliovirus 2C region functions during encapsidation of viral RNA. J. Virol. 71, 8759-8765. doi: 10.1128/JVI.71.11.8759-8765.1997

Verlinden, Y., Cuconati, A., Wimmer, E., and Rombaut, B. (2000). The antiviral compound 5-(3,4-dichlorophenyl) methylhydantoin inhibits the post-synthetic cleavages and the assembly of poliovirus in a cell-free system. Antiviral Res. 48, 61-69. doi: 10.1016/s0166-3542(00)00119-4

Wang, C., Jiang, P., Sand, C., Paul, A. V., and Wimmer, E. (2012a). Alanine scanning of poliovirus 2CATPase reveals new genetic evidence that capsid protein/2CATPase interactions are essential for morphogenesis. J. Virol. 86, 9964-9975. doi: 10.1128/JVI.00914-12

Wang, Y., Li, L., Hou, C., Lai, Y., Long, J., Liu, J., et al. (2016). SNAREmediated membrane fusion in autophagy. Semin. Cell Dev. Biol. 60, 97-104. doi: 10.1016/j.semcdb.2016.07.009

Wang, C., Ma, H. C., Wimmer, E., Jiang, P., and Paul, A. V. (2014). A C-terminal, cysteine-rich site in poliovirus 2C(ATPase) is required for morphogenesis. J. Gen. Virol. 95, 1255-1265. doi: 10.1099/vir.0.062497-0
Wang, T., Wang, B., Huang, H., Zhang, C., Zhu, Y., Pei, B., et al. (2017). Enterovirus 71 protease 2Apro and 3Cpro differentially inhibit the cellular endoplasmic reticulum-associated degradation (ERAD) pathway via distinct mechanisms, and enterovirus 71 hijacks ERAD component p97 to promote its replication. PLoS Pathog. 13:e1006674. doi: 10.1371/journal.ppat.1006674

Wang, S. H., Wang, A., Liu, P. P., Zhang, W. Y., Du, J., Xu, S., et al. (2018). Divergent pathogenic properties of circulating coxsackievirus A6 associated with emerging hand, foot, and mouth disease. J. Virol. 92, e00303-e00318. doi: 10.1128/JVI.00303-18

Wang, J., Wu, Z., and Jin, Q. (2012b). COPI is required for enterovirus 71 replication. PLoS One 7:e38035. doi: 10.1371/journal.pone.0038035

Wei, C., Zheng, C., Sun, J., Luo, D., Tang, Y., Zhang, Y., et al. (2018). Viperin inhibits enterovirus A71 replication by interacting with viral 2C protein. Viruses 11:13. doi: 10.3390/v11010013

Wen, W., Yin, M., Zhang, H., Liu, T., Chen, H., Qian, P., et al. (2019). Seneca Valley virus $2 \mathrm{C}$ and $3 \mathrm{C}$ inhibit type I interferon production by inducing the degradation of RIG-I. Virology 535, 122-129. doi: 10.1016/j.virol.2019.06.017

Wu, K. X., Phuektes, P., Kumar, P., Goh, G. Y., Moreau, D., Chow, V. T., et al. (2016). Human genome-wide RNAi screen reveals host factors required for enterovirus 71 replication. Nat. Commun. 7:13150. doi: 10.1038/ncomms13150

Xia, H., Wang, P., Wang, G. C., Yang, J., Sun, X., Wu, W., et al. (2015). Human enterovirus nonstructural protein 2CATPase functions as both an RNA helicase and ATP-independent RNA chaperone. PLoS Pathog. 11:e1005067. doi: 10.1371/journal.ppat.1005067

Xie, J., Yang, X. H., Hu, S. Q., Zhan, W. L., Zhang, C. B., Liu, H., et al. (2020). Co-circulation of coxsackieviruses A-6, A-10, and A-16 causes hand, foot, and mouth disease in Guangzhou city, China. BMC Infect. Dis. 20:271. doi: 10.1186/s12879-020-04992-x

Yang, J., Xia, H., Qian, Q., and Zhou, X. (2015). RNA chaperones encoded by RNA viruses. Virol. Sin. 30, 401-409. doi: 10.1007/s12250-015-3676-2

Yi, Z., Fang, C., Zou, J., Xu, J., Song, W., Du, X., et al. (2016). Affinity purification of the hepatitis $\mathrm{C}$ virus replicase identifies valosin-containing protein, a member of the ATPases associated with diverse cellular activities family, as an active virus replication modulator. J. Virol. 90, 9953-9966. doi: 10.1128/JVI.01140-16

Yoneyama, M., and Fujita, T. (2008). Structural mechanism of RNA recognition by the RIG-I-like receptors. Immunity 29, 178-181. doi: 10.1016/j. immuni.2008.07.009

Yoneyama, M., Suhara, W., Fukuhara, Y., Fukuda, M., Nishida, E., and Fujita, T. (1998). Direct triggering of the type I interferon system by virus infection: activation of a transcription factor complex containing IRF-3 and CBP/ p300. EMBO J. 17, 1087-1095. doi: 10.1093/emboj/17.4.1087

Zell, R., Delwart, E., Gorbalenya, A. E., Hovi, T., King, A. M. Q., Knowles, N. J., et al. (2017). ICTV virus taxonomy profile: picornaviridae. J. Gen. Virol. 98, 2421-2422. doi: 10.1099/jgv.0.000911

Zheng, Z., Li, H., Zhang, Z., Meng, J., Mao, D., Bai, B., et al. (2011). Enterovirus $712 \mathrm{C}$ protein inhibits TNF-alpha-mediated activation of NF-kappaB by suppressing IkappaB kinase beta phosphorylation. J. Immunol. 187, 2202-2212. doi: 10.4049/jimmunol.1100285

Zoll, J., Heus, H. A., van Kuppeveld, F. J., and Melchers, W. J. (2009). The structure-function relationship of the enterovirus 3'-UTR. Virus Res. 139, 209-216. doi: 10.1016/j.virusres.2008.07.014

Zust, R., Cervantes-Barragan, L., Habjan, M., Maier, R., Neuman, B. W., Ziebuhr, J., et al. (2011). Ribose 2'-O-methylation provides a molecular signature for the distinction of self and non-self mRNA dependent on the RNA sensor Mda5. Nat. Immunol. 12, 137-143. doi: 10.1038/ni.1979

Conflict of Interest: The authors declare that the research was conducted in the absence of any commercial or financial relationships that could be construed as a potential conflict of interest.

Copyright (c) 2020 Wang, Wang, Zhao, Hua and Du. This is an open-access article distributed under the terms of the Creative Commons Attribution License (CC BY). The use, distribution or reproduction in other forums is permitted, provided the original author(s) and the copyright owner(s) are credited and that the original publication in this journal is cited, in accordance with accepted academic practice. No use, distribution or reproduction is permitted which does not comply with these terms. 